Federico Iborra Bernad

Dr. Arquitecto

Profesor Ayudante Doctor

Departamento de Composición Arquitectónica

Universitat Politècnica de València

\title{
De la basílica vitruviana a la basílica ilustrada
}

\author{
Keywords: Basilica, Neoclassicism, Perrault, Contant d'Ivry, Chalgrin, Villanueva
}

The basilical church model has been present in Christianity since the time of Constantine. Among its various variants and interpretations could be highlighted that developed in the France of the seventeenth and eighteenth centuries, characterized by lintel entablatures that support half-barrel vaults and which, ultimately, refers to a misreading of the vitruvian description of the Basilica of Fano. This important episode will be the renovating germ of neoclassical architecture, although the buildings we are about to treat are often obscured by the shadow of the paradigmatic church of Sainte-Geneviève in Paris which, however, abandons the original typology. In this text we propose a revision of the architecture of this time looking for a common thread connecting its main works, which try to explain themselves from not only historical or formal approaches, but also constructive ones.

\section{La descripción vitruviana de la Basilica de Fano}

Oon las basilicas capaces de la mayor majestad y belleza: asi lo determiné yo y dirigi en la de Fano, cuya proporción y simetría es la siguiente. La bóveda del espacio del medio entre las columnas es larga 120 pies: ancha 60. El pórtico alrededor de la bóveda, entre las paredes y las columnas, ancho 20 pies. Toda la altura de las columnas, incluso el capitel, es 50 pies: el diámetro 5. [...] Cuatro columnas por cabo toman la anchura del espacio del medio, contadas las angulares: a lo largo en la parte contigua al foro hay ocho, inclusas las mismas angulares. [...] Sobre las columnas por todo el edificio corre el madero mayor, compuesto de tres maderos juntos, alto cada uno dos pies [...] Sobre dicho madero a plomo de los capiteles hay unos pilares que sirven de sustentantes, altos tres pies, anchos cuatro en cuadro. Encima de ellos en contorno va un madero labrado [...] y sobre éste cargan los tirantes con sus cabrios [...] Subiendo las columnas toda la elevación de la basílica hasta el madero de la bóveda, parecen aumentar magnificencia al gasto hecho, $y$ autoridad del edificio. (Ortiz 1787: 109-111)

Así nos descrbe Vitruvio la basílica que construyó en Fano, en el Capitulo I de su Libro V, con un texto que siempre ha resultado muy sugerente para los arquitectos, aunque dando lugar a diversas interpretaciones a lo largo de los siglos (Calduch 2014). Uno de los puntos más oscuros es la supuesta presencia de una bóveda en el espacio central, algo que defendieron Cesariano (1521), Perrault (1673), Galiani (1758) y Ortiz (1787) al interpretar de esta forma el término latino testudo, que literalmente significa "tortuga".
Otros autores, como Palladio (1567) o Violletle-Duc (1863), ambos excelentes constructores, comprendieron que la palabra sólo podía referirse a un techo de madera -testugginecon cerchas a la vista. Sea como fuere, no nos interesa tanto la auténtica Basílica de Fano como la idea de estructura abovedada que de ella tuvieron los arquitectos franceses de los siglos XVII y XVIII.

\section{El Templo de Charenton y el modelo pro- testante}

Una de las primeras adaptaciones del arquetipo vitruviano de la Basílica de Fano para un edificio religioso parece haber sido el templo hugonote de Charenton, quizá buscando un modelo arquitectónico sancionado por la Antigüedad que pudiera constituirse como alternativa a la planta jesuítica católica. Hasta entonces los edificios protestantes franceses eran espacios muy modestos y los más grandes habían seguido el esquema del grand temple de la Calade (1565), en Nîmes, cuya enorme sala, de 30 x 48 metros, se cubría mediante una carpintería de madera apoyada sobre un arco central de entre $35 \mathrm{y}$ 40 metros de luz, que algunos autores han querido ver inspirado en el puente romano de Gard (Chareyre 2017).

Tras la proclamación del Edicto de Nantes (1598) los reformados parisinos acometieron la construcción de lo que iba a ser el centro de culto hugonote más importante de toda Francia, situado en la capital, donde se recibiría a los grandes del reino y a los príncipes y embajadores extranjeros. Aunque el Edicto permitía la libertad de culto, obligaba a que no hubiera ningún templo protestante a menos de cinco leguas del centro de París, por lo que los reformados escogieron inicialmente 
un solar en la pequeña población de Ablonsur-Seine, que distaba exactamente esa distancia de la capital. Entre 1599 y 1603 se levantó un edificio con capacidad para unas 1000 ó 2000 personas, pero el camino de tierra era largo e incómodo, inabarcable para ancianos, enfermos, mujeres embarazadas y niños, por lo que se solicitó al rey el permiso para construir un nuevo templo de mayores dimensiones en Charenton-Saint-Maurice, que sería edificado entre 1606 y 1607 según diseño del célebre arquitecto protestante Jacques II Androuet du Cerceau (1550-1614). Este primer "Templo de Charenton", con capacidad para 4000 personas, desapareció en 1621 a causa de un incendio provocado en una revuelta antiprotestante, siendo reconstruido de manera casi idéntica por Salomon de Brosse (1571-1626), sobrino de Androuet du Cerceau y arquitecto de moda en esos años. El segundo templo tampoco tendría una vida demasiado larga, pues fue derribado tras la revocación del Edicto de Nantes, en 1685 (Guicharnaud 1999).

Dada la importancia del edificio y su dramático final, se conservan diferentes vistas y una planimetría completa (figuras 1 y 2), que nos permiten conocerlo con bastante profundidad. Presentaba una planta rectangular de 19,5 x 33 metros, con 20 columnas gigantes que soportaban una doble tribuna perimetral. Encima de ellas había otras tantas pilastras menores en las que descansaba el entablamento y, sobre éste, en el espacio central, se extendía una falsa bóveda de madera colgada de la carpintería del tejado, de gran pendiente. El número de columnas y las proporciones en anchura y altura remiten al modelo vitruviano de Fano, aunque las dimensiones en planta se adaptan a las limitaciones del lugar y se duplica la tribuna para permitir un mayor aforo.

Algunos estudiosos, como Rosalys Coope (1972), han considerado que este edificio tuvo una gran repercusión posterior, pero autores más recientes como Cabanel (2012) sostienen que realmente no creó escuela en Francia, aparte de La Rochelle, el templo luterano de Saint-Martin de Montbéliard (16041607), todavía en uso, y la pequeña iglesia de Claye, en Brie, que sería un antiguo templo reconvertido. En el extranjero sí que habria tenido influencias importantes, como los templos construidos a su imagen, con menores dimensiones, en Amsterdam (iglesia de los Remonstrants, 1630), en Erlangen y cerca de Jauer (1654-1655), y sobre todo en Londres, con la iglesia anglicana de Saint-James (1676-
1684) en Picadilly, diseñada por Christopher Wren. En tiempos del Refugio o exilio de los hugonotes, su planta habría inspirado a los diseñadores de los templos de Copenhague (1688), de Cassel (edificado por Paul du Ry, pariente de Salomon de Brosse, en 1698), de Zell (1700), de la Fusterie o Templo nuevo en Ginebra (1715, del francés Jean Vennes), de Santo Espíritu en Berna (1729) y de Frankfurt-am-Oder (1736). Destacaria también el templo hugonote construido entre 1701 y 1705 en Berlin, en la Friedrichstädtischer Markt (actual Gendarmenmarkt) diseñado por los arquitectos hugonotes Louis Cayart y Abraham Quesnay. En Holanda podría hablarse de las sinagogas portuguesa (16701675) y askenazi (1670-1671) de Amsterdam,
Figura 1. Salomon de Brosse. Sección longitudinal y planta del Templo de Charenton (Marot 1680: 131r).

Figura 2. Salomon de Brosse. Sección transversal fugada del Templo de Charenton (Marot 1680: 130r).
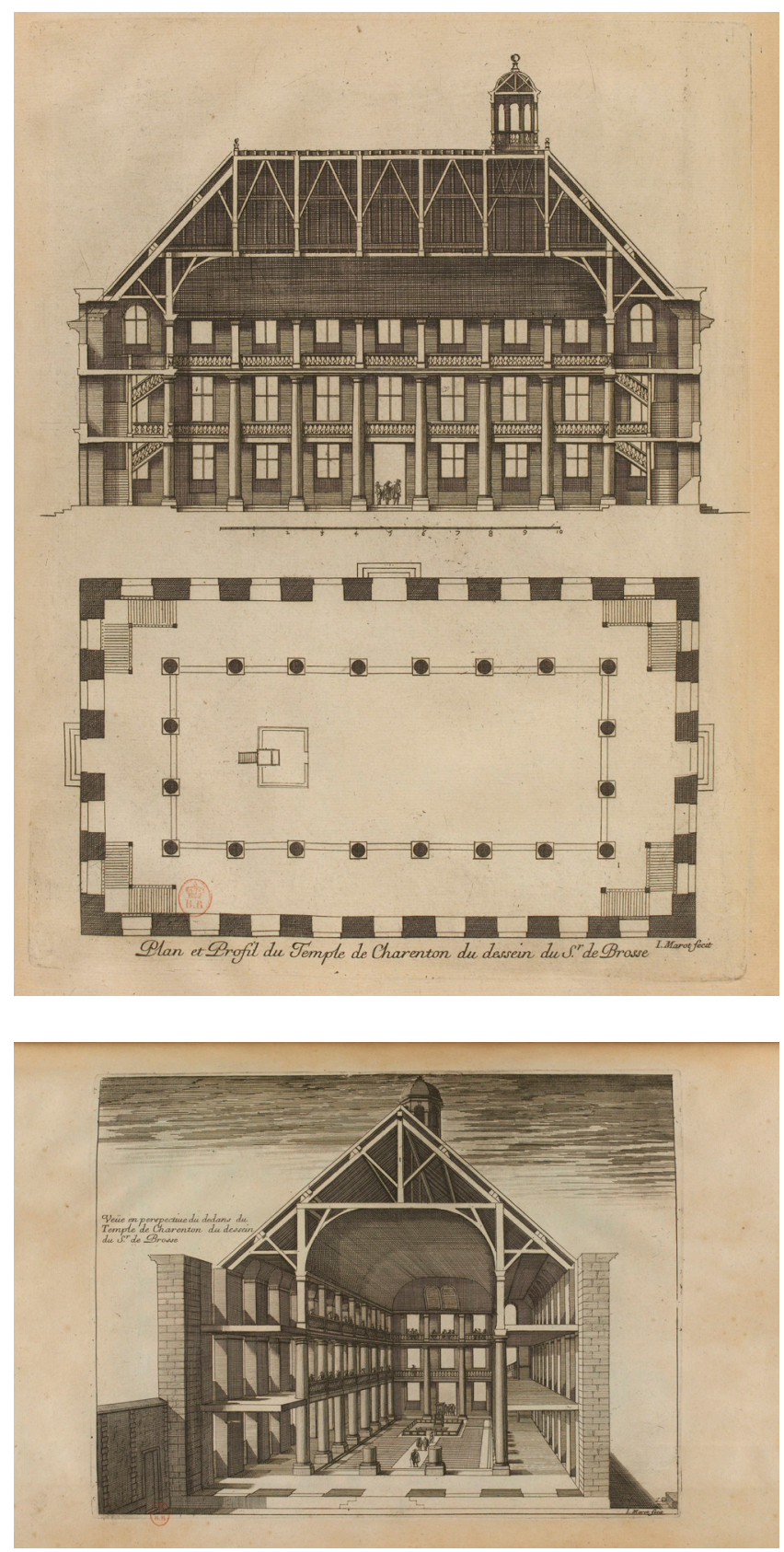

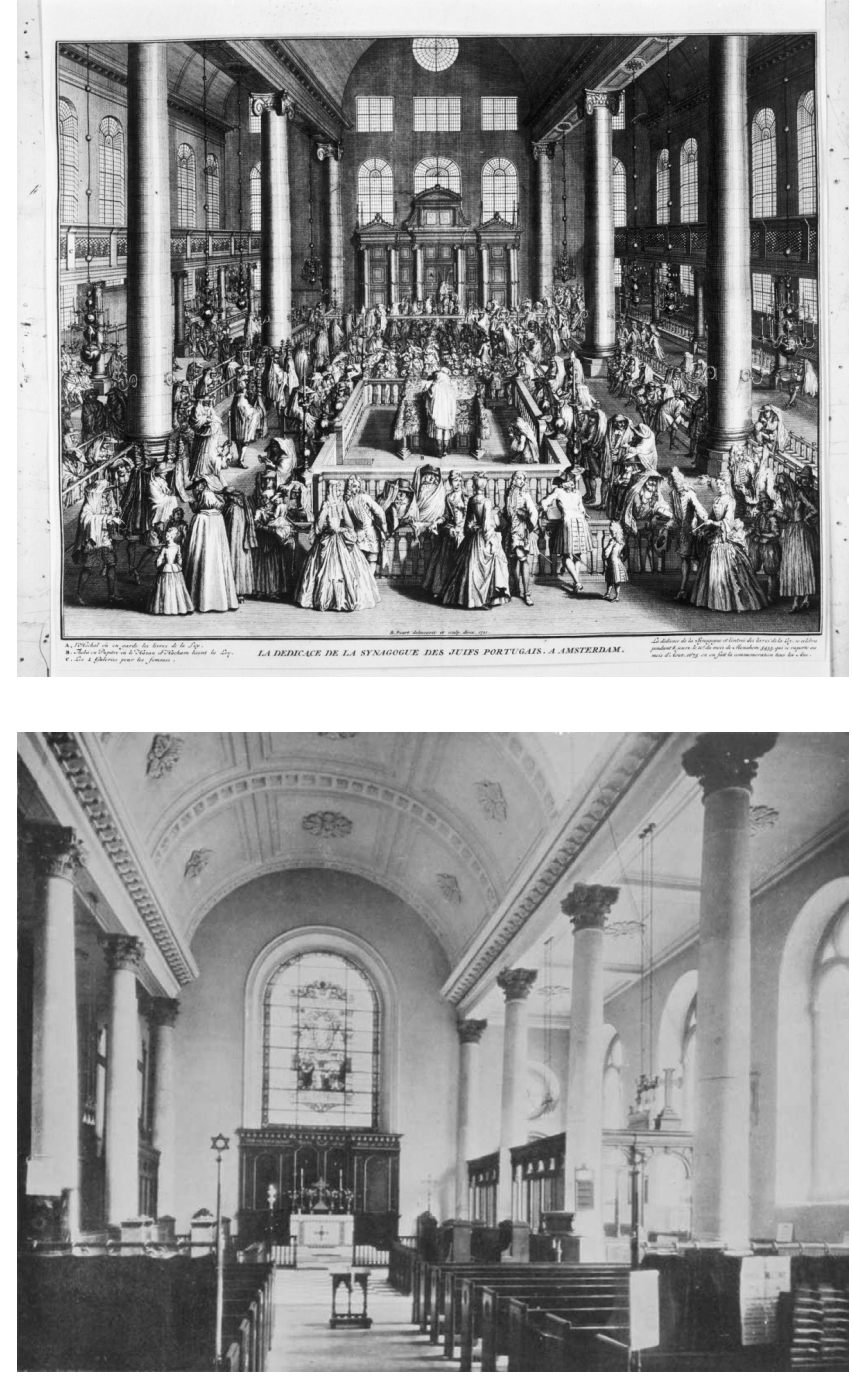

Figura 3. Elias Bouman. Sinagoga portuguesa de Amsterdam. Grabado de Bernard Picart, 1721. Fuente: Wikimedia Commons.

Figura 4. Christopher Wren. Iglesia de St. Mary Aldermanbury (1670-86), antes de su bombardeo en la Segunda Guerra Mundial (Royal Comission 1929: lámina 77).

Figura 5. Claude Perrault. Restitución de la planta de la Basílica de Fano (Perrault 1673: 144)

Figura 6. Claude Perrault. Sección trasversal fugada de la Basílica de Fano (Perrault 1673: 146). así como la sinagoga portuguesa de La Haya (1726) cuyo arquitecto, Daniel Marot (16611752) era un hugonote refugiado en Holanda, hijo de Jean Marot, autor del grabado con la sección y perspectiva de Charenton.

De todos estos ejemplos nos interesan principalmente aquéllos fechados en el siglo XVII que presentan un único orden de grandes columnas que soportan arquitrabes adintelados y una bóveda de madera de medio cañón. Estariamos hablando (figuras 3 y 4) de las dos sinagogas de Amsterdam, construidas por Elias Bouman a partir de 1670, y de varias iglesias menores de Christopher Wren -y Robert Hooke- como St. Mary Aldermanbury (1671-1681) o St. Magnus the Martyr (16711687). ${ }^{1}$ Frente al modelo basilical de Fano, en todas ellas se ha perdido la tribuna perimetral y se impone una mayor direccionalidad con la supresión de las columnas de los pórticos extremos, anunciando una tipología que tendrá su apogeo en la Francia católica de mediados del siglo XVIII.

\section{Del Vitruvio de Perrault hasta los escritos de Cordemoy}

En paralelo a las experiencias holandesas y británicas, surgiría en Francia un interés creciente por las estructuras adinteladas, que fructificará en un animado debate y la realización de algunas de las obras más importantes de la arquitectura de su tiempo. El comienzo de este fenómeno se puede situar en una de las reconstrucciones gráficas más conocidas de la Basílica de Fano, la publicada por Claude Perrault en 1673, dentro de la primera edición de su traducción de los Diez Libros de Vitruvio. Esta propuesta, comparada con las desarrolladas por otros autores, ha sido estudiada en profundidad por el profesor Juan Calduch (2014).

Perrault preparó dos láminas para su libro: la planta (Perrault 1673: 144) y una sección trasversal parcial fugada (Perrault 1673: 146). En ellas (figuras 5 y 6) no cuestionaba la solución palladiana, aunque señala en sus comentarios y notas que habia introducido algunos cambios para corregir lo que creía que eran carencias o interpretaciones equivocadas. Su planta, de hecho, repite fielmente la propuesta de Palladio incluyendo el pórtico
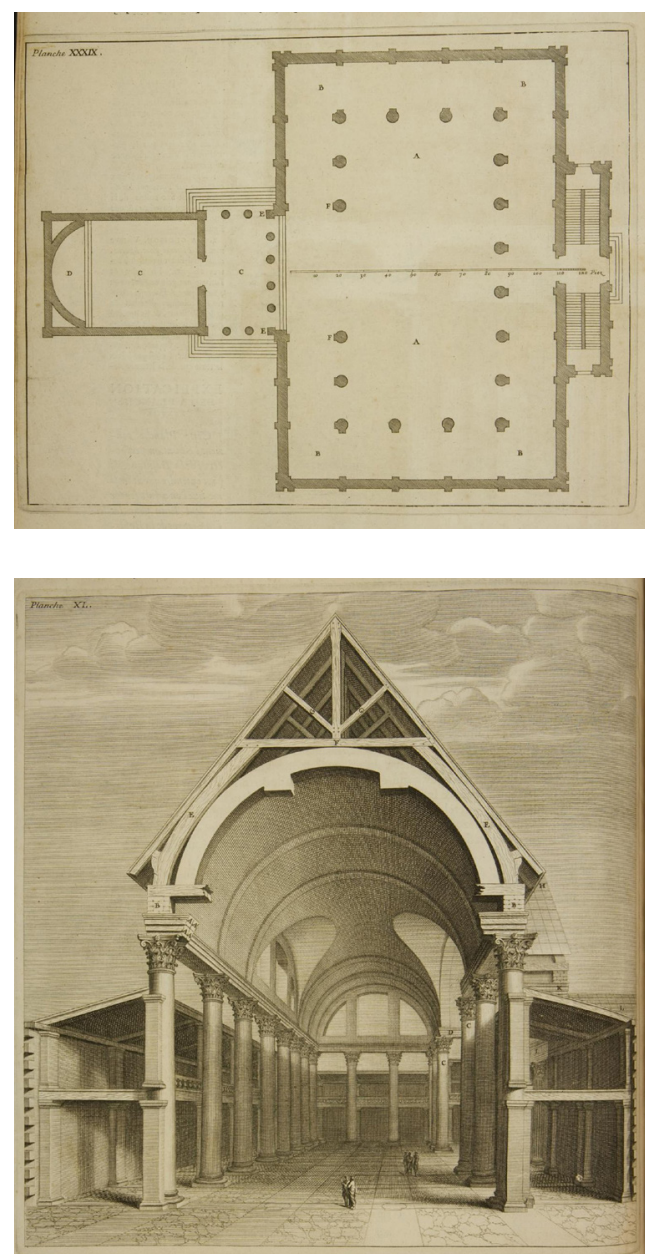
del templo abierto lateralmente al exterior, y situando las escaleras ante el acceso, articulando también el muro con pilastras y abriendo ventanas en los rellanos.

Se aleja más del modelo palladiano en la sección, donde destaca la enorme bóveda de cañón fajonada de madera, que justifica en una de sus notas "Es verdad que Vitruvio ha tomado una especie por otra, poniendo testudo en vez de fornix [...] hay tres clases de bóvedas: a saber fornix que es de cañón [en berceau], testudo que es de arista [en cul de four] y concha que es en trompa [en trompe]. En cuanto a la dificultad que se podría encontrar en la anchura de la bóveda, sería razonable si esta bóveda fuera de piedra, pero era de madera" (Perrault 1673: 144-145).

La extraña solución de la carpinteria, netamente francesa por la gran pendiente de sus faldones, guarda grandes similitudes con la representada en el grabado del Templo de Charenton. Teniendo en cuenta que el edificio protestante pervivió hasta 1685, parece impensable que Perrault no lo conociera, por lo que bien le podría haber servido de inspiración para su reconstrucción de la Basílica de Fano, como ya observó Petzet (1957).

Es dificil establecer un juicio claro sobre el estilo personal de Claude Perrault como arquitecto y su aportación a las grandes obras en las que participó, ya que todos sus dibujos, recopilados tras su muerte por su hermano Charles en dos volúmenes, desaparecieron en el incendio que en 1871 destruyó la Biblioteca del Louvre. Sin embargo, sí que se conservan en la Biblioteca de Santa Genoveva de París los seis dibujos de un proyecto fechado en 1697 para la reedificación de la cercana iglesia medieval de Sainte-Geneviève, perteneciente a los frailes agustinos. Claude habia fallecido en 1687, pero parece que la propuesta fue dibujada en la década de 1670 o de 1680 , habiéndose retrasado su ejecución probablemente a causa de la guerra (1688-1697) de la Liga de Augsburgo (Petzet 1957).

Lo más interesante del proyecto es su sección (figura 7) que, frente al modelo jesuítico, presenta la atrevida innovación de sustituir las arcadas por un esquema porticado trilitico, suprimiendo en planta los grandes contrafuertes que se descomponen aquí entre las columnas y el muro, unidos superiormente por una especie de arbotantes, como se hacía en las iglesias góticas. La imagen final guarda grandes semejanzas con la restitución que Perrault habia hecho de la Basílica de Fano, aunque no se trata de una traslación tan literal del modelo como la que realizó
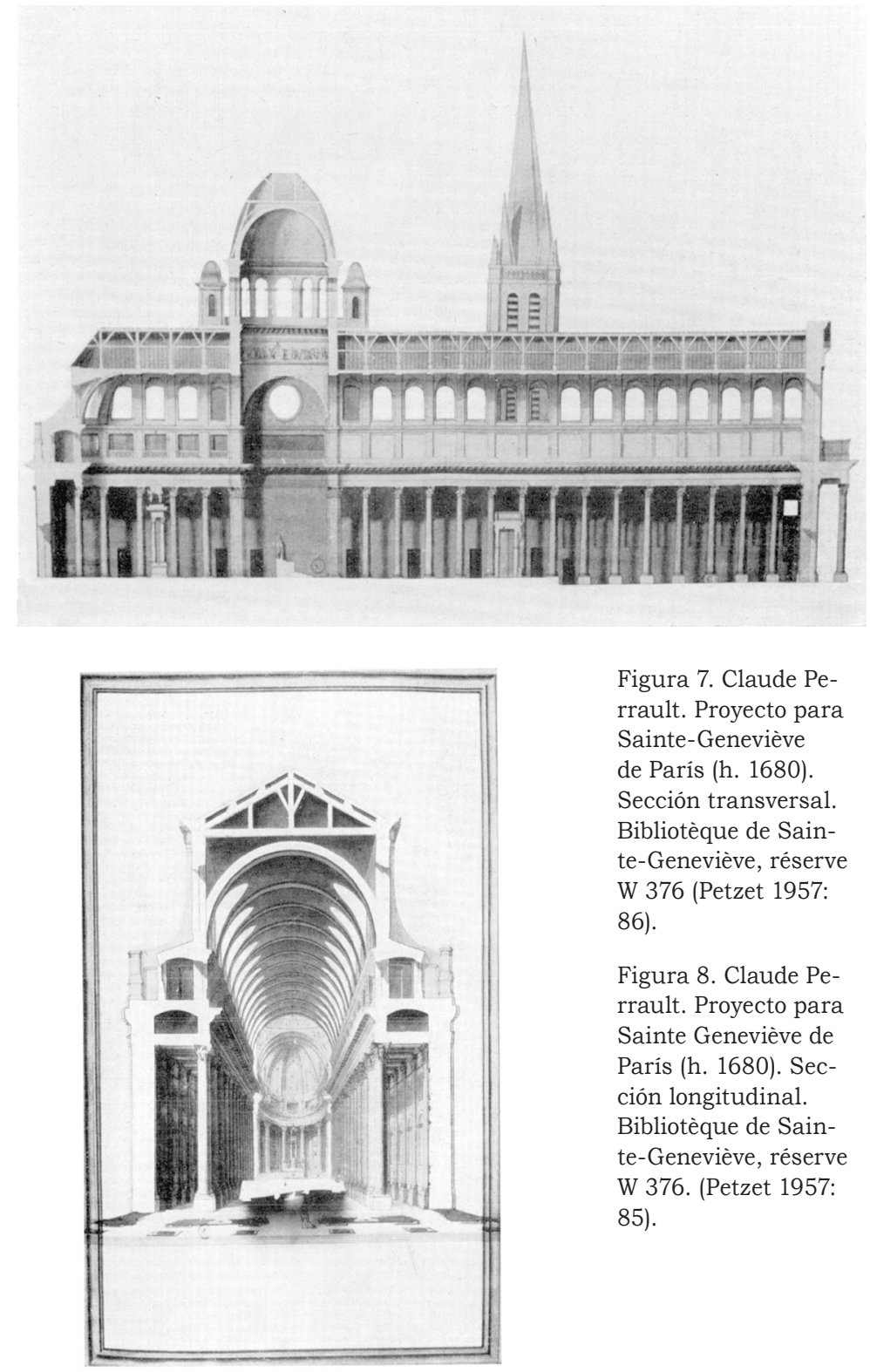

Figura 7. Claude Perrault. Proyecto para Sainte-Geneviève de París (h. 1680). Sección transversal. Bibliotèque de Sainte-Geneviève, réserve W 376 (Petzet 1957: 86).

Figura 8. Claude Perrault. Proyecto para Sainte Geneviève de París (h. 1680). Sección longitudinal. Bibliotèque de Sainte-Geneviève, réserve W 376. (Petzet 1957: $85)$.
Androuet du Cerceau en Charenton. Así, en la bóveda de medio cañón se incorporan lunetos con grandes ventanas caladas, siendo las diferencias todavía más patentes al revisar el resto de los planos y sobre todo la planta, extraordinariamente larga, que duplicaba la longitud de la iglesia medieval e introducía además una cúpula sobre un transepto no emergente (figura 8). Su disposición, que culmina en un ábside con deambulatorio también apoyado sobre columnas, responde en gran medida a esquemas propios del gótico francés. ${ }^{2}$

Quizá no sea casual que por las mismas fechas en que Perrault preparaba su proyecto para Sainte-Geneviève, el abate Claude Fleury publicaba Moeurs des israelites (1681) y Moeurs des chrestiens (1682). Este influyente religioso -confesor de Luis XV y preceptor 
Figura 9. Jules Hardouin-Mansart. Capilla del Palacio de Versalles. Tribuna en la planta superior. Fotografía de David Iliff. (Wikimedia commons).

Figura 10. Claude Perrault. Esquema de armado de hierro en la Columnata del Louvre (Patte 1769: L. XIII)

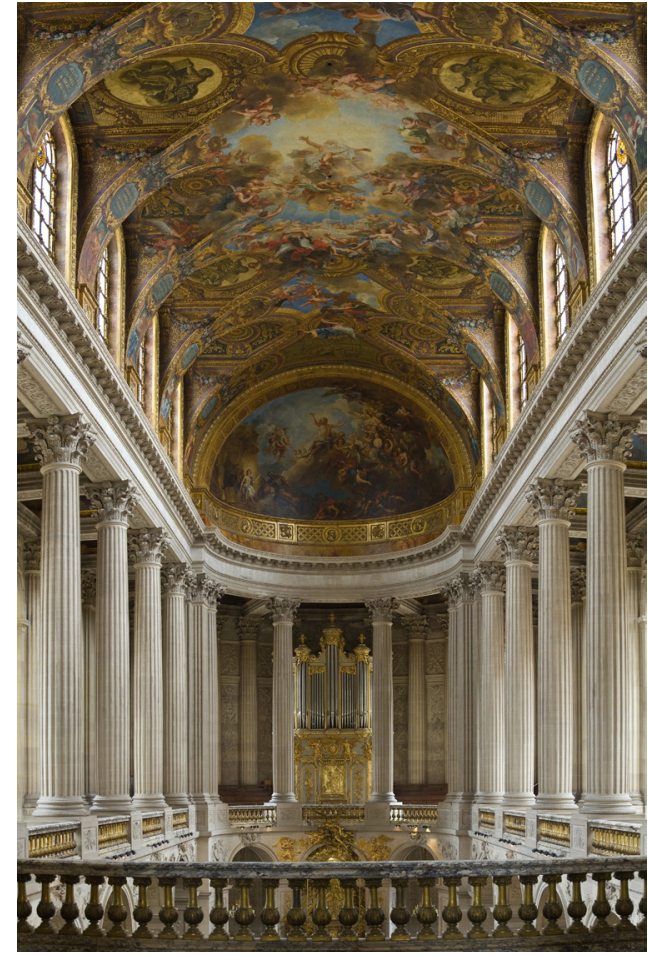

de sus hijos, además de autor de una Historia de la Iglesia y un Catecismo- concebía el templo cristiano como un lugar sagrado que infundiese respeto y piedad, rechazando el fasto secular que ofendia y dañaba los sentidos. Identificaba al obispo con el magistrado en la basílica romana o el presidente del sanedrin de los judios, rodeado de los presbiteros a modo de jueces. Buscaba la semejanza de las iglesias católicas con las antiguas basílicas descritas por Vitruvio y también con las del primer cristianismo, de tres naves divididas por órdenes de arquitectura, con celdas a los lados a modo de capillas para orar o meditar, columnas de mármol con remates de bronce dorados y presbiterios elevados en semicírculo, con bóveda en forma de nicho. ${ }^{3}$ Es, por tanto, más que probable que hubiera relación entre las reivindicaciones de Fleury y la erudita adopción de un modelo basilical romano por parte de Perrault.

El proyecto para Sainte-Geneviève o algún otro diseño perdido de Perrault podría haber influido decisivamente en la solución para la capilla de Versalles (1688-1710), obra maestra de Jules Hardouin-Mansart (figura 9), a la que Blondel dedica todo el capitulo VIII de su Libro VII y cinco láminas de su tratado (1756: 142-152), alabando su belleza y ejecución. Como acertadamente afirma Emil Kaufmann (1955, 129), "La capilla es un triunfo del estilo de Perrault" y, de alguna manera, su diseño se puede relacionar con la "Sala egipcia" de Vitruvio (Perrault 1673: 206, lámina LIV) o sobre todo con los "Piliers de Tutèle" en Burdeos, con sus arcadas sobre un pórtico adintelado, que Claude Perrault había conocido y dibujado en 1669 (Paris, BnF, ms. Fr. 24713 , ff $127 v^{\circ}-128$ ) y que Pierre Lepautre grabó para la segunda edición de su Vitruvio (1684: 219). En Versalles, exteriormente podemos comprobar la pervivencia de los contrafuertes propuestos para Sainte-Geneviève, convertidos aquí en verdaderos arbotantes al no existir el deambulatorio oculto del proyecto de Perrault. Igualmente las naves laterales, con dinteles entre el muro y cada columna, remiten al modelo materializado por el tratadista en la fachada del Louvre, sin cuya audaz solución constructiva, descrita por Patte

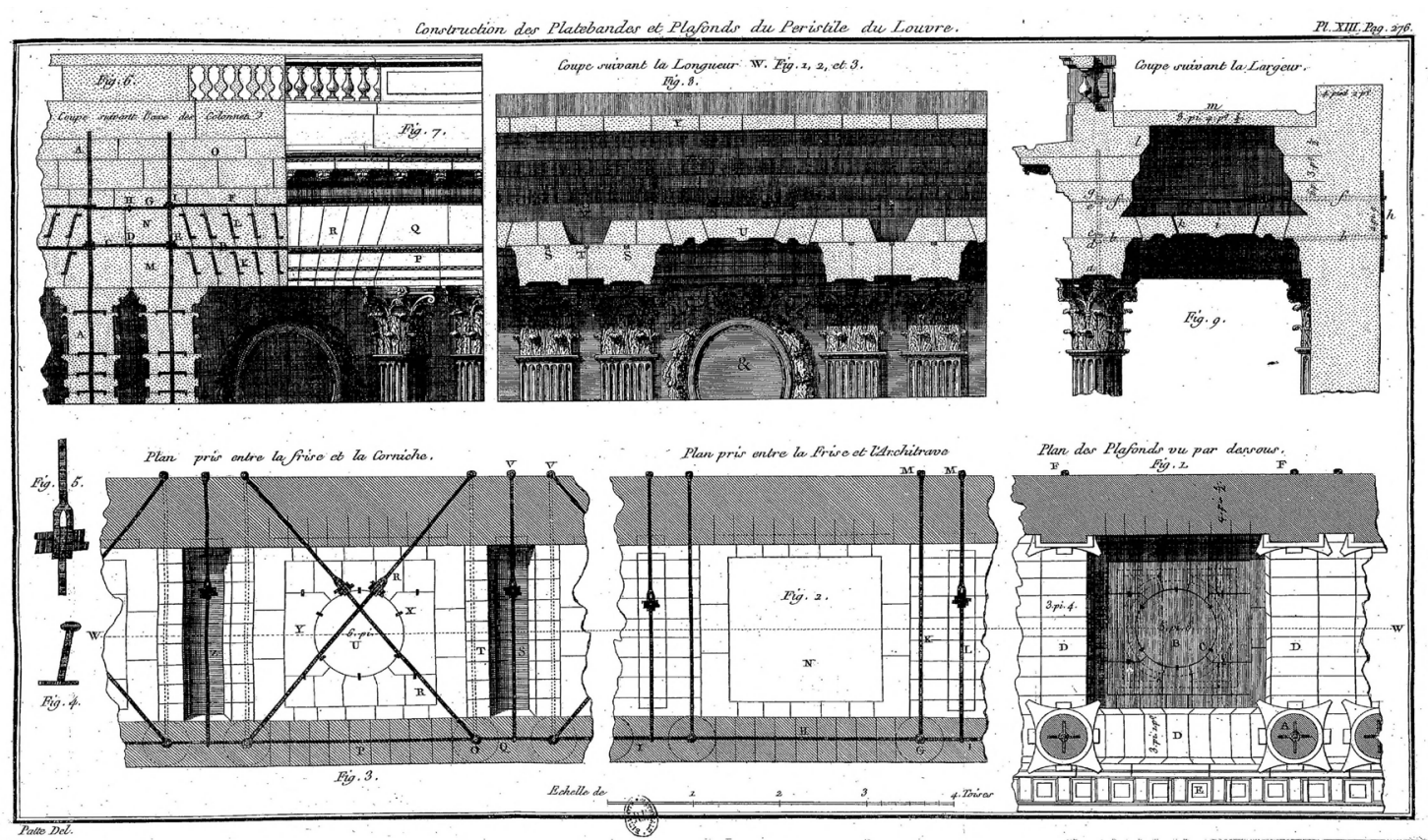


(1769: 269-274), se hace impensable la arquitectura arquitrabada que estamos analizando (figura 10).

La obra de Perrault y sobre todo la capilla del palacio de Versalles influirán en el desarrollo de una nueva estética arquitectónica. Será el abate Jean-Louis de Cordemoy quien, en su Nouveau Traité de toute l'Architecture (1706) plantee la búsqueda de la verdad estructural de los elementos arquitectónicos inspirándose en modelos góticos y griegos, proponiendo la conjunción del sistema trilitico clásico con la potente verticalidad de las catedrales medievales. De manera provocadora y con un extremismo de ascendencia jansenista llegará a descalificar incluso la basílica de San Pedro de Roma, criticando la solución de las arcadas sobre las que descansa la cúpula y evocando la simplicidad, ligereza y conveniencia lógica de los espacios internos de los templos de la "santa Antigüedad", para concluir con la propuesta de un rediseño hipotético de San Pedro, con columnas y arquitrabes en sustitución de pilastras y arcos.

Las ideas de Cordemoy serian rebatidas por Amédée François Frézier, enzarzándose ambos en una disputa a través de una serie de artículos aparecidos entre 1709 y 1712 en la revista Mémoires de Trevoux, publicada por los jesuitas. En la segunda edición de su Nouveau Traité (1714) Cordemoy sintetizará sus argumentos bajo el título Dissertation sur la manière dont les églises douvent être bâties, respondiéndole Frézier en la Dissertation historique sur les Ordres d'Architecture (1738), incluida en el Traité de Stéréometrie (1737-
1739). Este último autor era ingeniero, por lo que evitará los argumentos teológicos y escogerá el punto de vista técnico para rebatir las ideas de Cordemoy, poniendo de manifiesto su inconsistencia estructural (Gravagnuolo 2010: 7-16). Pero a mediados de siglo resurgirán las ideas del religioso y conseguirán materializarse en algunos de los hitos más importantes de la arquitectura francesa.

\section{Laugier, Soufflot y Contant d'Ivry}

Al repasar la historia de la arquitectura francesa, resulta sorprendente o cuanto menos llamativo confirmar la escasa repercusión que tuvieron las ideas de Cordemoy y la solución de la capilla de Versalles durante la primera mitad del siglo XVIII. ${ }^{4}$ Esto parece dar la razón a Frézier sobre las dificultades técnicas de este tipo de construcciones, ya que los dinteles de la capilla de Versalles están armados con hierro y la mayor parte del peso de la cubierta realmente se absorbe por los muros perimetrales (Edmunds 2002: 33, 98-99). No debe extrañarnos, por tanto, que una de las principales secuelas de esta estructura, la capilla del castillo de Lunéville, realizada por German Boffrand -discipulo y colaborador de Jules HardouinMansart- entre 1720 y 1723, se resolviera con estructura de madera. ${ }^{5}$ En paralelo, en la Inglaterra del período georgiano se construyeron múltiples iglesias con bóvedas de cañon de madera, siguiendo las propuestas de Wren tras el incendio de Londres (Curt 2002: 110-111). Muchas de ellas presentan arcos, pero otras se resuelven con pórticos adintela-
Figura 11. Jules Hardouin-Mansart. Capilla de Versalles (1688-1710). Sección longitudinal (Blondel 1756, IV, L. 21).

Figura 12. Jules Hardouin-Mansart. Capilla de Versalles (1688-1710). Sección transversal (Blondel 1756, IV, L. 23).
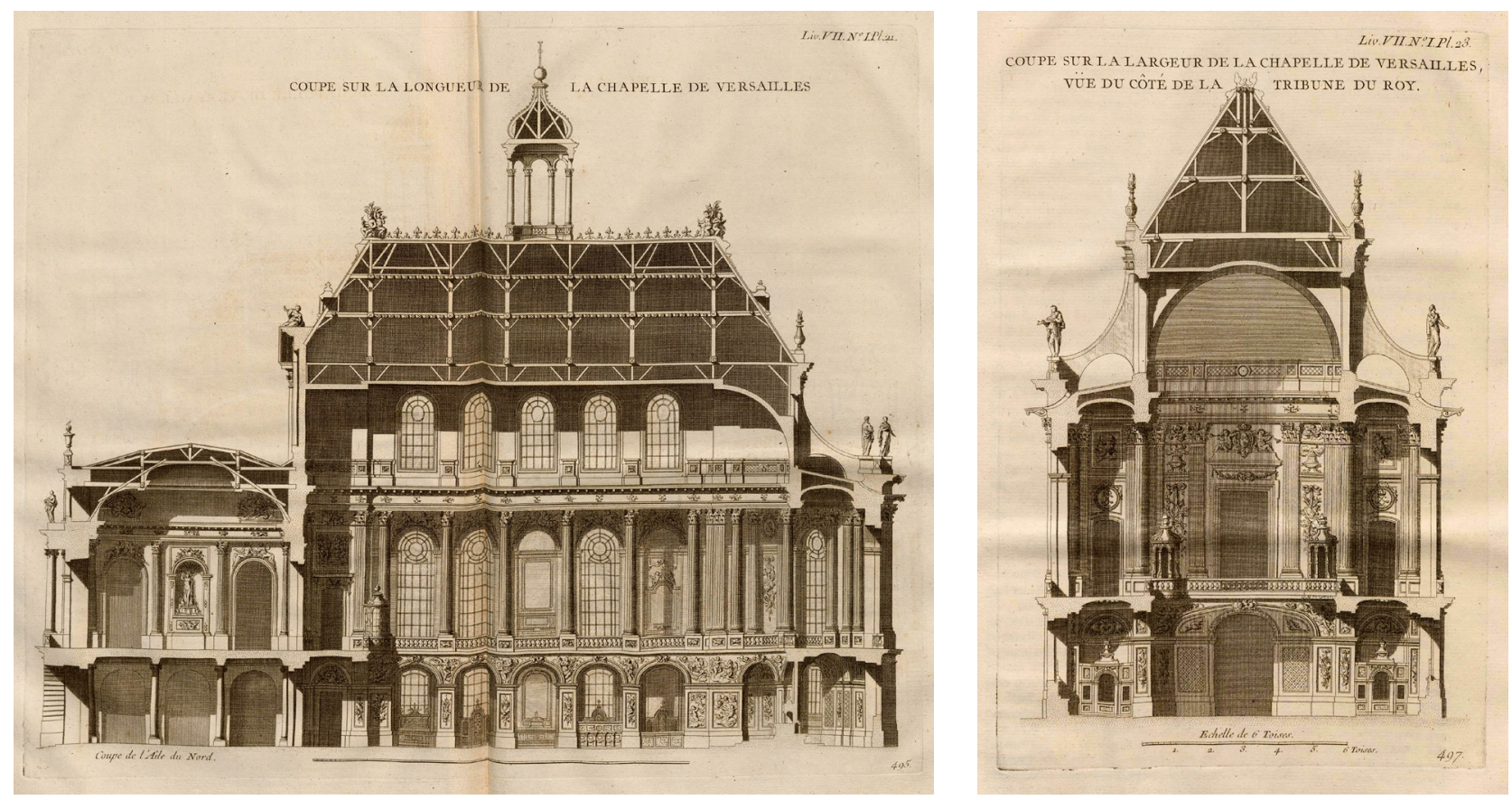


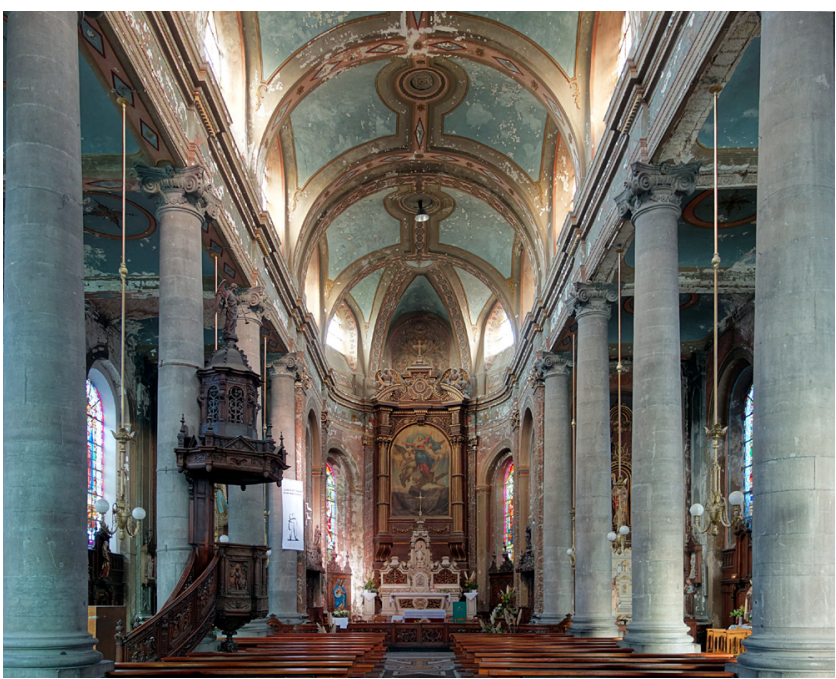

Figura 13. Pierre Contant d'Ivry. Interior de la iglesia de Saint-Wasnon en Condé-sur-l'Escaut (1751-1756). Fotografía de Velvet (Wikimedia commons). dos, como St. Lawrence en Mereworth (17441746) y -con bóvedas rebajadas- Holy Trinity en Leeds (1721) o All Saints en Gainsborough, Lincolnshire (1736-1744). Las dos últimas incorporan ábsides, aproximándose al modelo de los templos católicos.

A mediados del siglo XVIII resurgirá en Francia el interés por las iglesias basilicales. Siguiendo la estela marcada por Cordemoy, será el jesuita Marc-Antoine Laugier en su Essai sur l'architecture (1753) quien reivindicará las bondades de una arquitectura adintelada para los templos religiosos, tomando como referencia la capilla de Versalles (figuras 11 y 12). Al igual que ocurriera unas décadas antes, los argumentos de Laugier serán rebatidos por el influyente crítico de arte Étienne Lafont de Saint-Yenne en el Examen d'un essai sur l'architecture, avec quelques remarques sur cette science traitée dans l'esprit des beaux-arts, al que Laugier responde con un párrafo añadido en la segunda edición de su obra, publicada en 1755: "El autor del examen asegura que el ejemplo de la capilla de Versalles no prueba nada. Abra los ojos, dice él, y verá que estas columnas se apoyan sobre un estilóbato con arcadas en planta baja que es lo que visualmente le da la solidez. Pero yo le pregunto, por mi parte: si eliminamos esta planta baja, que es el mayor defecto de la capilla, elevando un forjado al nivel de los arcos, de modo que fuéramos a pie llano desde la tribuna real hasta el órgano, ¿la capilla perdería su solidez? Sin duda no... Pues bien, si juzgamos que fuera necesario un estilóbato como éste debajo de las columnas, no hay más que construir un subterráneo bajo el pavimento de la iglesia." (Laugier 1755:181). ${ }^{6}$

Estas ideas planteadas por Laugier habían tenido ya una aplicación pionera, pocos años antes, en la pequeña iglesia de Saint-
Wasnon en Condé-sur-l'Escaut, al norte de Francia (1751-1756). Se trata de un templo de planta basilical, con pórticos adintelados que en la nave central se cubren mediante bóvedas vaídas y en las laterales con bóvedas esquifadas de escasa flecha, conformando un techo casi plano (figura 13). La fuente de inspiración última parece ser la capilla de Versalles, aunque podría añadirse alguna influencia británica, puesto que las bóvedas vaídas y la solución de la cabecera recuerdan a lo proyectado por Christopher Wren para la catedral de Saint Paul de Londres (16691711). ${ }^{7}$

A nivel constructivo, lo más interesante de Saint-Wasnon es que carece de arbotantes, lo que implica que los empujes de la bóveda principal son nulos o muy reducidos. Por su curvatura podemos descartar que ésta sea una estructura de madera, lo que sólo deja como alternativa que se trate de bóvedas tabicadas, de gran ligereza.

La autoria de la iglesia de Saint-Wasnon se atribuye a Pierre Contant d'Ivry, artista con gran prestigio en su labor de interiorista, diseñador de mobiliario y de jardines. Contant ha sido considerado junto a Gabriel uno de los arquitectos con más talento de su generación aunque para algunos autores (Braham 1980: 50), frente a la consistencia estilistica de éste, Contant parece más bien haber sido un excéntrico superdotado. En todo caso, resulta muy sospechosa la falta de interés por su innovador proyecto basilical, patente en el hecho de que en sus Oeuvres (1769) únicamente publicó una fachada, distinta además de la ejecutada. Es por ello probable que actuara como asesor, revisando una propuesta del diletante Emmanuel de Croÿ-Solre (17181784), joven principe de Condé-sur-l'Escaut, que por esas fechas estaba muy interesado por la arquitectura. ${ }^{8}$

En 1750, ante la ruina del antiguo templo de Saint-Wasnon, las autoridades locales decidieron su reconstrucción encargando el proyecto a un maestro de obras local. Sin embargo, Crö̈-Solre decidió implicarse y consultar la propuesta "al más famoso arquitecto de París, que se llama Contant”. Éste rechazó el proyecto porque utilizaba demasiada madera, que con el tiempo se pudriría, planteando una solución mediante bóvedas tabicadas. ${ }^{9}$ También se le consultó por las mismas fechas sobre el diseño del Hospital General de Hainaut en la cercana población de Valenciennes (1751-1767), proyectado por el ingeniero provincial Charles-Toussaint Havez (Joudiou 1986). ${ }^{10}$ 
La nueva estructura de Saint-Wasnon se resolveria sobre columnas de piedra y dinteles o platabandas de ladrillo, con arcos de descarga ocultos a la altura de los frisos y tirantes de hierro por debajo, que iban de una columna a otra. Parece que Contant preparó varios diseños ligeramente diferentes, entre los que el príncipe escogió -según relata en sus memorias- el de proporciones más esbeltas, por ser el que más se aproximaba a la capilla de Versalles. Sin embargo, los detalles menores y la decoración fueron dibujados por el propio aristócrata, dando su aprobación el veterano arquitecto (Joudiou 1986).

Emmanuel de Croÿ-Solre formaba parte de la corte de Luis XV y conocía de primera mano la capilla de Versalles, aunque es dificil saber si en el caso de Saint-Wasnon existia además una reflexión sobre los escritos de Cordemoy y las ideas -todavía inéditas- de Laugier, o simplemente se pretendía evocar la arquitectura más representativa de la monarquia. Por otro lado, a la hora de considerar las posibles influencias británicas, resulta sugerente recordar la larga estancia involuntaria en Londres del Mariscal de Belle-Isle, tío político de Croÿ-Solre ${ }^{11}$ y responsable de la difusión de las bóvedas tabicadas en Francia.

La bóveda tabicada es un invento hispánico, cuyos referentes más antiguos se sitúan en la zona de Valencia, en el siglo XIV. La facilidad y rapidez de ejecución, que no necesita del apoyo sobre cimbras, llevó a esta técnica a una gran difusión (Zaragozá 2012). Su implantación en Francia tiene su origen cuando los territorios españoles del Rosellón fueron cedidos por Felipe IV a la Corona francesa en 1659. Desde ese momento la técnica se empleará en varios conventos en Languedoc, incluyendo el de Toulouse, a partir de 1705. El primer edificio civil de cierta importancia en el que se puede encontrar la bóveda tabicada, más allá de las tierras limitrofes a las antiguas fronteras, será el castillo de Bizy en Vernon, ampliado por Contant d'Ivry para el Mariscal de Belle-Isle en la década de 1740 (Bannister 1968; González 2004: XXIII).

$\mathrm{El}$ arquitecto incluyó orgullosamente las fachadas de los establos del castillo de Bizy entre las láminas de sus Oeuvres (1769), aunque no aparecen secciones que muestren sus interiores abovedados. No obstante, debió quedar tan fascinado por las posibilidades que ofrecía la técnica constructiva, que la incorporará en otras obras suyas como la Abadia de Penthemont (1747), el castillo de Arnouville (1750), la iglesia de Saint-Wasnon (1751) en Condé-sur-l'Escaut o el ala nue- va del Palais Royal de París (1753) (Joudiou 1986).

No obstante, el mayor impulso en la difusión de la técnica constructiva se debe al Conde d'Espie, quien en 1750 contrató a los obreros de Bizy ${ }^{12}$ para que le construyeran en Toulouse una residencia y publicó en 1754 un librito titulado Manière de rendre toutes sortes d'édifices incombustibles ou Traité sur la Construction des voûtes faites avec des briques et du plâtre, dites voûtes plates; et d'un toit de brique, sans charpente, appelé comble briqueté. El libro estaba dedicado al Mariscal de Belle-Isle, como no podía ser de otro modo, aunque fue Emmanuel de Croÿ-Solre quien presentó en la corte al caballero d'Espie después de haber "trabajado varias veces, en invierno, para corregir y perfeccionar su obra" (Moulin 1991).

La experiencia de Saint-Wasnon debió servir a Contant d'Ivry para que en 1757 se
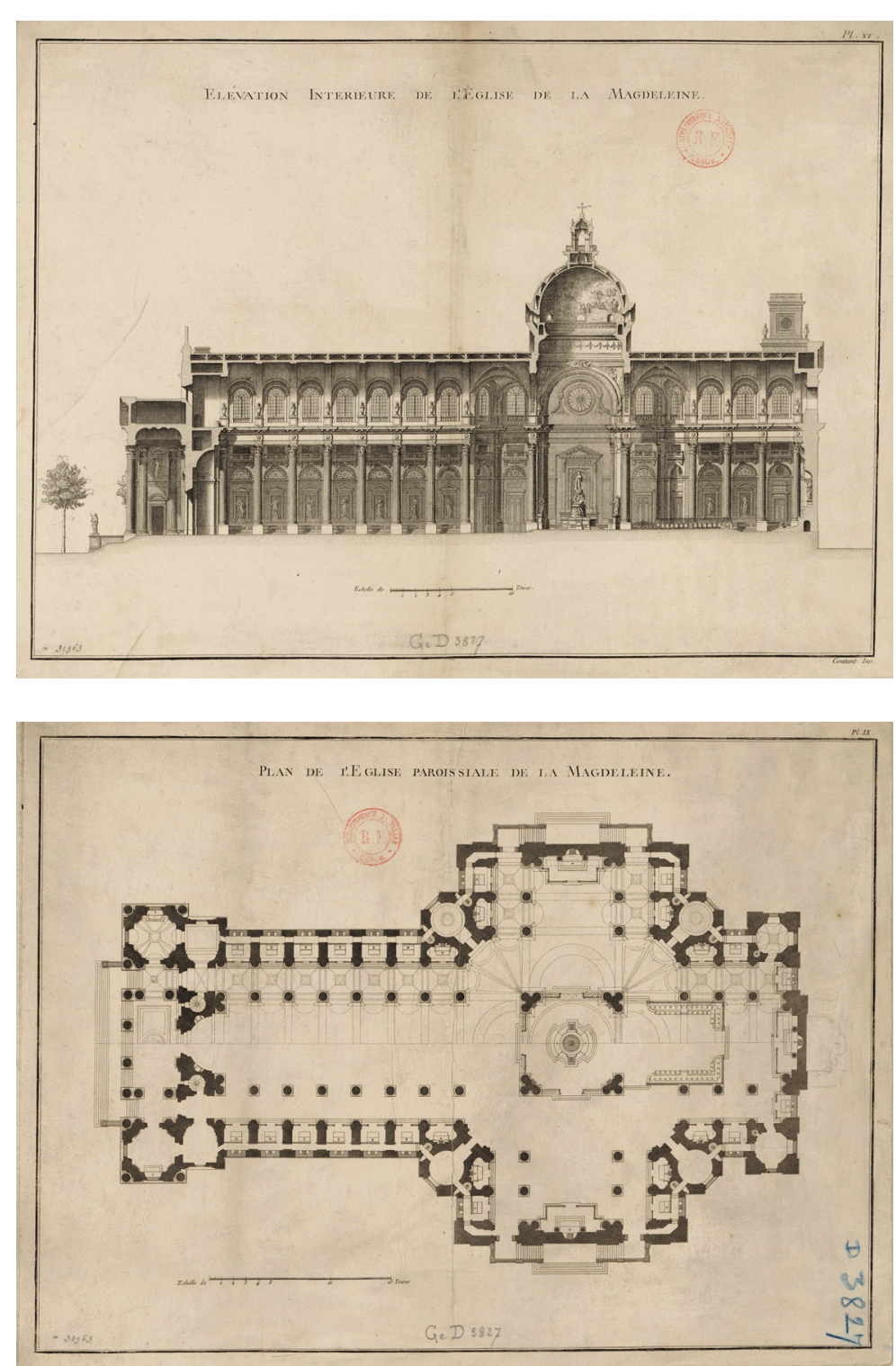

Figura 14. Pierre Contant d'Ivry. Sección del proyecto (1757) para la iglesia parroquial de la Madeleine. Bibliothèque nationale de France, GED-3827 (XI). Fuente: Gallica.fr

Figura 15. Pierre Contant d'Ivry. Planta del proyecto (1757) para la iglesia parroquial de la Madeleine. Bibliothèque nationale de France, GED-3827 (IX). Fuente: Gallica.fr 
le encargase el proyecto para La Madeleine de París, sin duda la obra más importante de su carrera. Presentaba una planta cruciforme con una cúpula central, inspirada en Los Inválidos, ${ }^{13}$ pero con las naves resueltas mediante un pórtico adintelado de gran altura y enormes ventanas en el segundo cuerpo, desmesuradas si consideramos los modelos basilicales romanos (figuras 14 y 15). En su forma y proporciones nos remiten al piso alto la capilla de Versalles, reproducido por Blondel (1756: 142-152) y, de hecho, da la sensación de que Contant aquí recoge literalmente la propuesta de Laugier (1755) de proyectar una iglesia tomando como referencia la obra de Hardouin-Mansart, pero prescindiendo de la planta baja. La bóveda dibujada, por su espesor, parece pensada para ser ejecutada en piedra, aunque sobre ella se suprime la madera del tejado, confiando el apoyo de la cubierta a una segunda hoja abovedada de fábrica, probablemente tabicada. En 1763 se colocó la primera piedra, pero a su muerte (1777) había avanzado bastante poco y el proyecto fue modificado por su discipulo Guillaume-Martin Couture, con un nuevo diseño que tampoco se llegó a completar. No obstante, de haberse ejecutado según el primer plan previsto, el aspecto de la nave de La Madeleine se parecería al de la catedral de Saint-Vaast en Arras (figura 16), dibujada por Contant entre 1773 y 1774 aunque concluida en $1834 .{ }^{14}$

Es llamativa la gran similitud del pro-

Figura 16. Pierre Contant d'Ivry. Interior de la catedral de SaintVaast en Arras (17731834). Fotografia de Jiel Beaumadier (Wikimedia commons). yecto presentado en 1762 por el arquitecto valenciano Vicente Gascó, para su nombramiento como Académico de San Fernando, con la propuesta de Contant d'Ivry para La Madeleine. ${ }^{15}$ Aunque Gascó no se atrevió a introducir la bóveda en su propuesta, la sec-

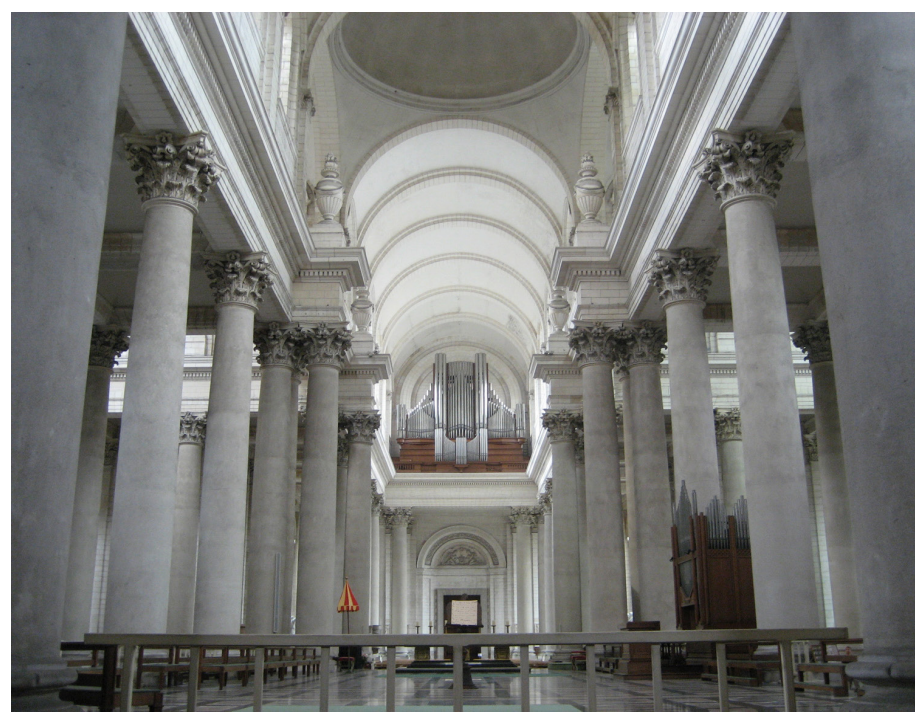

ción longitudinal y la transversal remiten al cuerpo alto de la capilla del Louvre, como proponía Laugier, siendo muy sospechosa la presencia de un nártex similar al de la parroquia francesa y la misma solución de los frentes de las capillas laterales.

No obstante, el valedor más notable de las ideas de Laugier sería Jacques-Germain Soufflot (1713-1780), quien ya habia expresado su interés por la ligereza de la arquitectura medieval en su Mémoire sur l'architecture gotique (1741), presentada el 12 de abril de ese año ante la Académie de Beaux-Arts de Lyon y veinte años más tarde, el 22 de diciembre de 1761, ante la Académie Royale d'Architecture (Petzet 1961: 135-142). Su obra maestra es, sin duda, la iglesia de Sainte-Geneviève (1755-1790), con una propuesta alternativa a la ya comentada de Perrault y planteada para una ubicación diferente. No nos detendremos en esta gran pieza, por ser sobradamente conocida y porque su interior presenta una imagen bastante alejada de una basilica convencional. Únicamente nos interesa recordar que en las primeras versiones Soufflot (1757: L. 4) pretendia resolver el tejado sin madera, disponiendo una segunda bóveda independiente de la visible desde el interior, aunque finalmente se optó por una cubrición convencional, mucho más ligera, que muestran los planos de Lequeu (1780). La obra se comenzó en 1764 , año en que Le Roy le dedicaría, junto a La Madeleine, entusiastas comentarios en el último capítulo de su Histoire, esperanzado en que el éxito de ambas pudiera implicar una gran aportación francesa en la Historia de la Arquitectura (Le Roy 1764: 76-89).

Soufflot podria estar detrás de la iglesia de Notre-Dame-Saint-Vincent (1759-1789) en Lyon, realizada por un arquitecto local poco conocido llamado Léonard Roux (Braham 1980: 123). Debemos tener en cuenta que la orden de los agustinos era la misma que tutelaba el templo de Sainte-Geneviève de París (Kalnein 1995: 169) y sobre todo que Soufflot trabajó en Lyon hasta 1755. Notre-DameSaint-Vincent es una obra interesante por su temprana cronología, con una nave de orden dórico, cubierta por una bóveda de medio cañón con grandes lunetos semicirculares y cúpula sobre un transepto ligeramente emergente, que interrumpe las columnatas (figuras $17,18,19$ y 20). Constructivamente se resuelve de manera bastante convencional, con una pesada bóveda de medio cañón con lunetos encajada entre gruesos contrafuertes y una sobrecubierta de madera a cuatro aguas. 

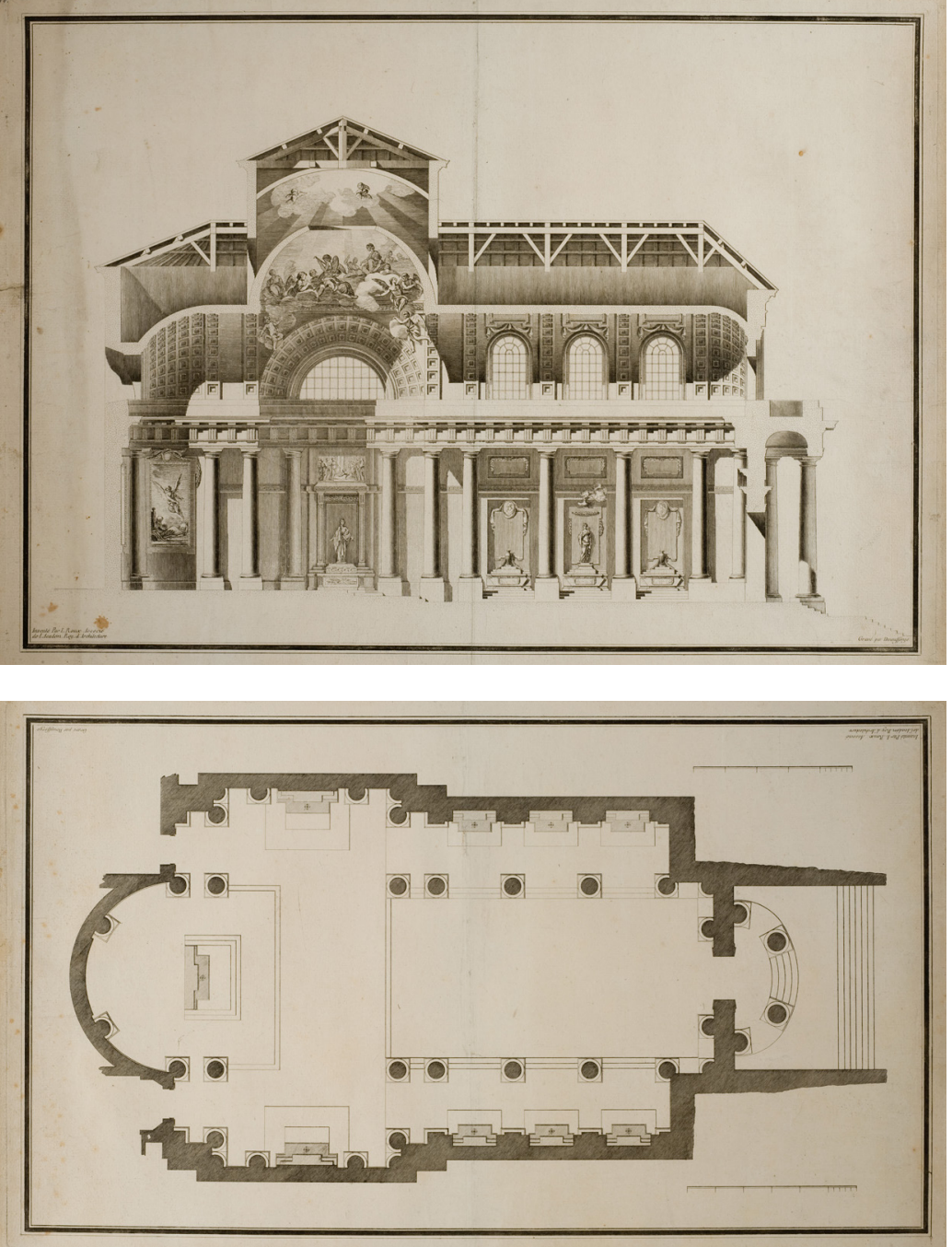

\section{Las basilicas neoclásicas de la década de 1760 y sus secuelas}

Todos los ejemplos anteriores, vinculados a las experimentaciones de Contant d'Ivry y Soufflot, siguen la estela de la capilla del Louvre al funcionar con grandes intercolumnios de la misma anchura que las naves laterales y, como ocurre en las iglesias góticas, evitan cargar los entablamentos gracias al empleo de lunetos en las bóvedas. Será, sin embargo, en la década 1760 cuando se defina en Francia un nuevo tipo de iglesias basilicales con bóvedas de cañón mucho más rotundas y pesadas, apoyadas en pórticos adintelados más tupidos. Las ideas de Cordemoy y Laugier, las propuestas de Perrault para Sainte-Geneviève, la esbeltez y ligereza de las catedrales góticas y el interés por la reconstrucción de las basílicas paleocristianas están detrás de todas ellas. Pero este nuevo grupo no puede entenderse sin tener en cuenta la recuperación arqueológica de la Antigüedad, sea a través de las restituciones del Templo de Baalbek (figura 21) hechas por Jean Marot

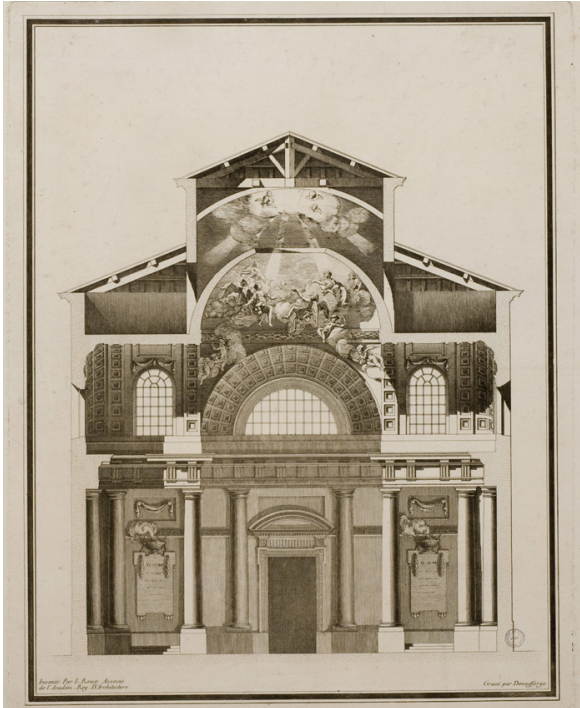

Figuras 17, 18 y 19. Léonard Roux. Sección longitudinal, sección transversal y planta de la iglesia de Notre-Dame-Saint-Vincent de Lyon (1759) Bibliothèque municipale de Lyon, Coste 433c, 433d y 433b.

Figura 20. Léonard Roux. Iglesia de Saint-Vincent de Lyon (1759). Estado actual. Fotografia de Alexandre Norman (Wikimedia commons).

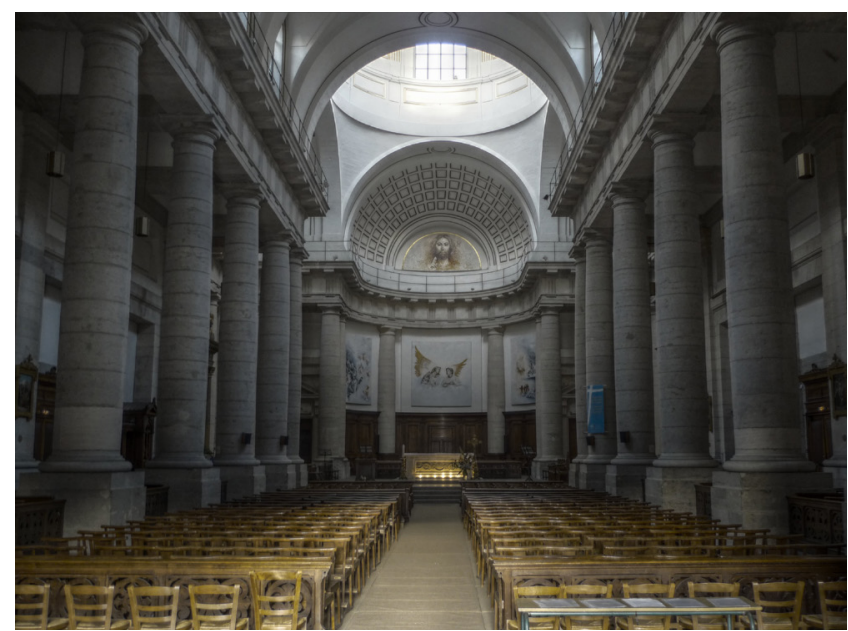


Figura 21. Sección transversal fugada del Templo de Baalbek (Marot 1680: 141r).

Figura 22. Nicolas-Marie Potain. Proyecto para la iglesia de Saint-Louis en Saint-Germain-enLaye (1765). (Braham 1980:125)

Figura 23. Mathurin Crucy. Vista actual del interior de la Catedral de Rennes (1786), modificado sobre el proyecto original de Nicolas-Marie Potain (1764). Fotografia de Tango7174 (Wikimedia Commons).

Figura 24. LouisFrançois Trouard. Iglesia de Saint-Symphorien de Versalles (1764-1770). Óleo de Pierre-Antoine Demachy (1772). Fotografia por gentileza de Philippe Bedin.
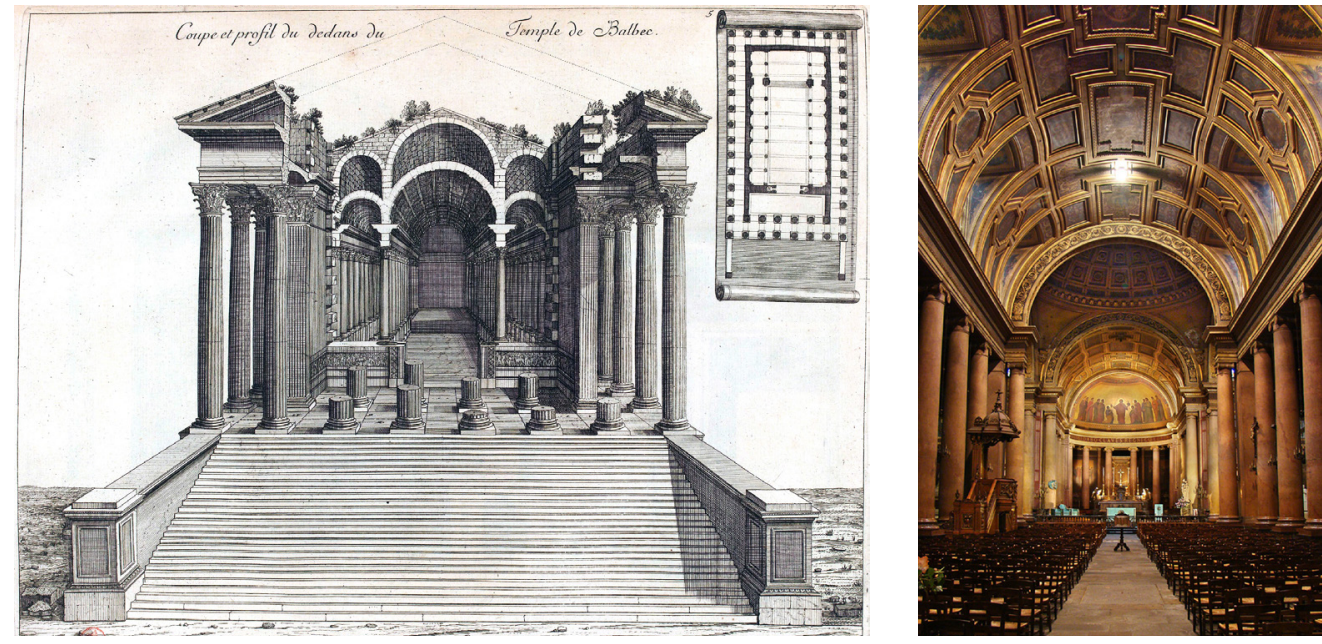

VUE JNTERIEURE DE L'EGLLSE PAROISSLALE D̃E S"GERMAIN "EN LAVE *
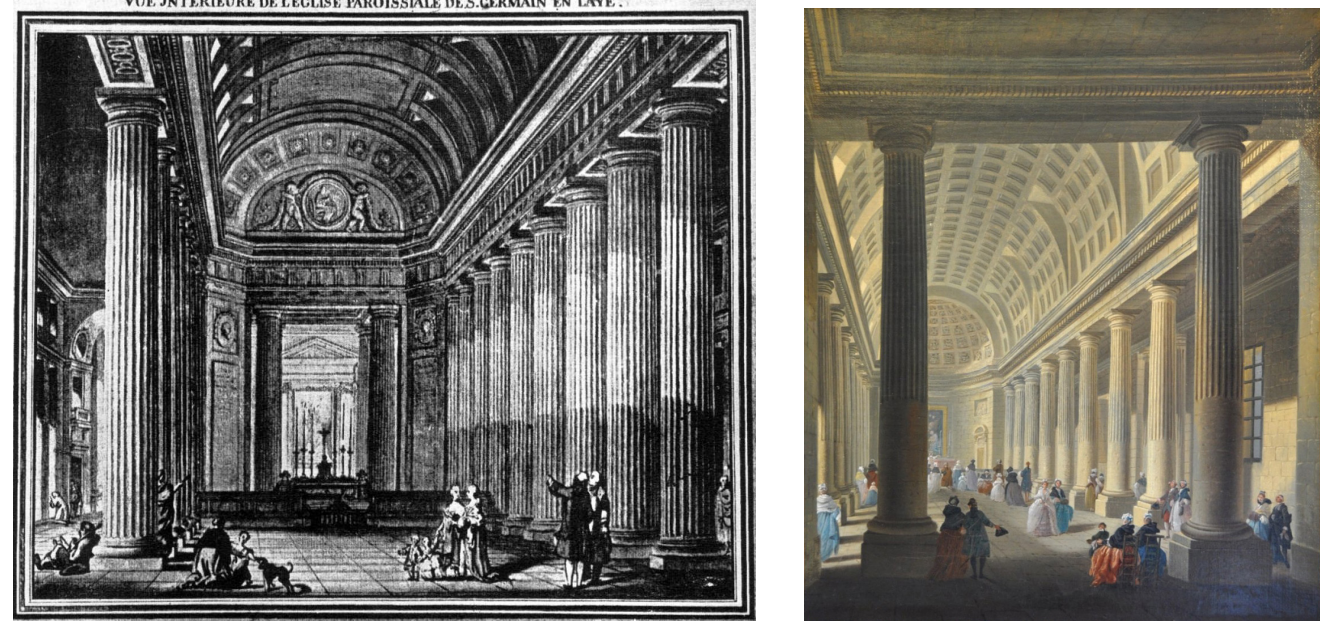

tectos implicados obtuvieron el Premio de la Academia y pudieron conocer estas obras de primera mano en Roma.

La renovación tipológica suele vincularse al trio formado por Potain, Trouard y Chalgrin (Braham 1980: 123-136). NicolasMarie Potain, coetáneo de Soufflot y colaborador de Gabriel, que había obtenido el Premio de Roma en 1738 y en 1767 publicó el Traité des ordres d'architecture, uno de los últimos libros sobre los órdenes arquitectónicos donde recomienda, entre otras cosas, que no se adosen las columnas a los muros porque entonces perderian su ligereza y gracia. Proyectó en 1762, bajo la supervisión de Soufflot, la reconstrucción de la catedral de Rennes con columnas soportando dinteles, aunque la planta puramente basilical se retrasaría hasta 1765, con su propuesta (figura 22) para la sustitución de la pequeña iglesia parroquial de Saint-Germain-en-Laye, encargada por Luis XV para este dominio real cercano a París (Braham 1980: 124-126). Ninguna de las dos se concluyó según lo previsto, aunque lo finalmente ejecutado para Rennes, según proyecto de Mathurin Crucy
(1786), podria respetar las ideas principales de la propuesta de Potain (figura 23). ${ }^{16}$ Ambas se caracterizan por sus singulares lunetos adintelados, que parecen más propios de una estructura de madera que de fábrica. ${ }^{17}$

Mejor fortuna tendria la iglesia de SaintSymphorien en Montreuil -un barrio de Versalles- proyectada por Louis-François Trouard en 1764 y completada en seis años (figuras 24). Trouard era bastante más joven que Potain, pues nació en 1729, y también obtuvo el Premio de Roma en 1753. En la década de 1760 trabajó como Inspector del palacio real y después como arquitecto municipal de Versalles, convirtiéndose en miembro de la Academia en 1767. El templo está dedicado a Saint-Symphorien, martirizado en Autun en el siglo II, lo que justifica una sobria planta basilical de inspiración tardoantigua, carente de capillas laterales. Su interior se resuelve con gran austeridad, empleando columnas de orden dórico carentes de acanaladuras en la parte inferior de su fuste, algo reservado normalmente a los vestíbulos y zonas de mucho tránsito. Los casetones originalmente estaban decorados con rosetas únicamente en el 

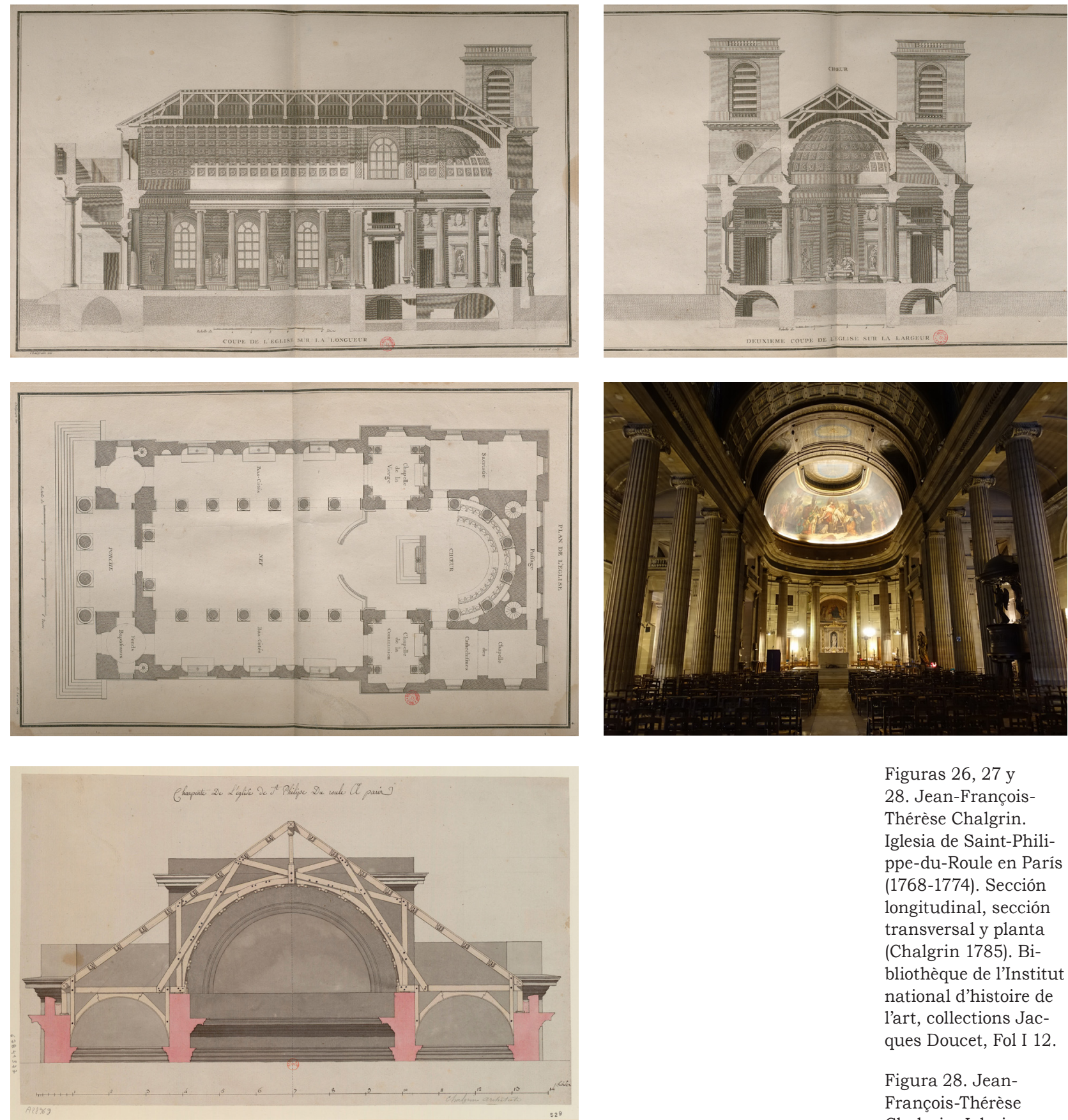

Figuras 26, $27 \mathrm{y}$ 28. Jean-FrançoisThérèse Chalgrin. Iglesia de Saint-Philippe-du-Roule en París (1768-1774). Sección longitudinal, sección transversal y planta (Chalgrin 1785). Bibliothèque de l'Institut national d'histoire de l'art, collections Jacques Doucet, Fol I 12.

Figura 28. JeanFrançois-Thérèse Chalgrin. Iglesia de Saint-Philip-

ábside, resaltando la sobriedad de la bóveda de la nave, que apoya sobre un friso carente de metopas y triglifos (Braham 1980: 126-128). A diferencia de los edificios anteriores, las naves laterales presentan bóvedas continuas que podrian remitir a la imagen que Marot ofrece del Templo de Baalbek. Exteriormente presenta una serie de pequeños arbotantes ocultos por la fachada, solución similar a la empleada por Soufflot para Sainte-Geneviève y que confirma que la bóveda es de fábrica.

De las grandes basílicas de la Ilustración la más magnífica, sin embargo, es la que construyó Jean-François-Thérèse Chalgrin entre 1768 y 1774 para la parroquia de Saint-
Philippe-du-Roule, en París. Chalgrin había nacido en 1739, en el seno de una familia humilde. Se formó en el estudio de Servandoni $y$, tras abandonarlo, fue uno de los primeros pupilos de Boullée. También parece que conocia bastante bien a Soufflot antes de 1758, año en que obtuvo el Premio de Roma, donde permaneció hasta 1763. Una vez en París trabajó para el Ayuntamiento, entablando amistad con el conde de Saint-Florentin, Ministro y Secretario de Estado de la Casa Real, para el que realizó diversos trabajos y que parece ser el responsable de la adjudicación del proyecto de Saint-Philippe-du-Roule (Braham 1980: 128-129). pe-du-Roule en París (1768-1774). Estado actual. Fotografía de Guilhem Vellut (Wikimedia Commons).

Figura 29. JeanFrançois-Thérèse Chalgrin. Proyecto final para la carpintería de Saint-Philippe-du-Roule (BNF, RESERVE FOL-VE-53 (E)). Fuente: Gallica.fr. 

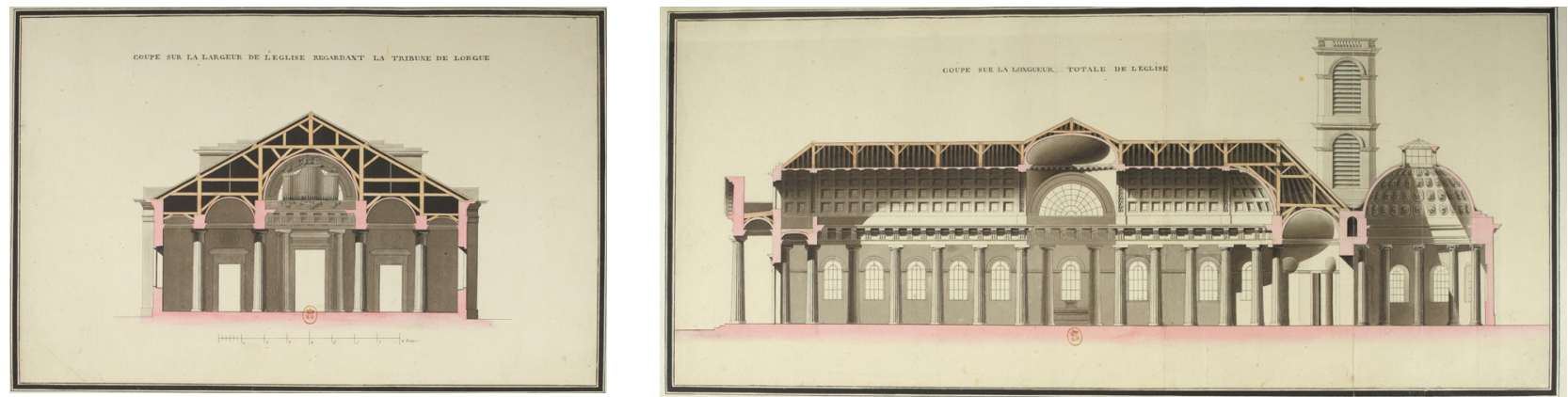

Figuras 30, 31 y 32 Mathurin Cherpitel. Proyecto para la iglesia de Saint-Pierre-duGros-Caillou (1775). Sección transversal, sección longitudinal y planta. (BNF, PETFOL-HA-68, f. 13, f. 11, f. 5). Fuente: Gallica.fr.

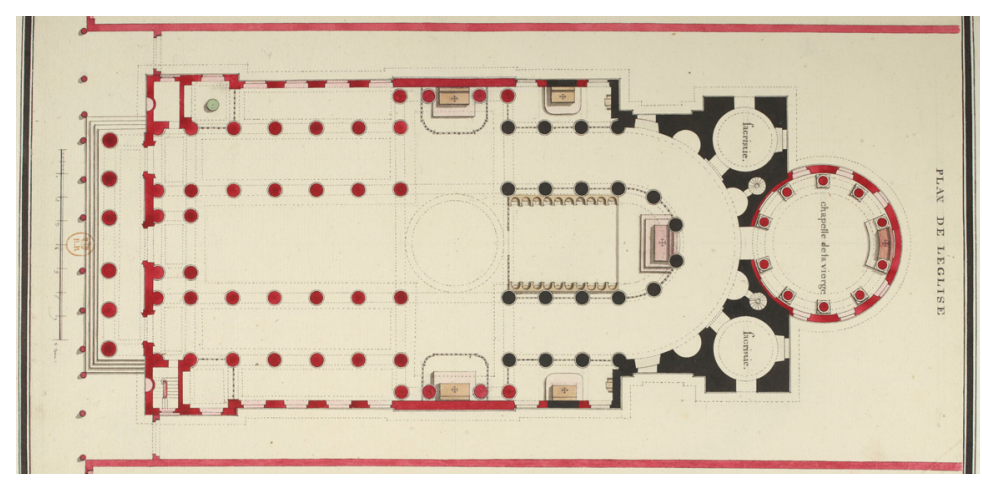

Aunque la iglesia en muchos aspectos remite a Saint-Symphorien, el edificio de Chalgrin es mucho más complejo. Sitúa varios altares bajo las ventanas y presenta vestigios de un transepto (la Capilla de la Virgen y la Capilla de la Comunión) que se muestran tanto al exterior como al interior, interrumpiendo la columnata en la posición del altar mayor, donde además se producía la única perforación de la rotunda bóveda de medio cañón decorada con casetones cuadrados. Ésta culmina en un ábside bajo el que se prolongaba la columnata por delante del muro curvo de la cabecera evocando una falsa girola, si bien a mediados del siglo XIX se amplió el templo y se creó una girola real (figuras 25 , 26, 27 y 28).

Exteriormente tenía previstas dos filas de grandes arbotantes (figura 27) pero que finalmente no fueron necesarios porque, por razones de economía, la bóveda se ejecutó en madera (figura 29). Tampoco se construyeron los campanarios que, inspirados en el proyecto para Sainte-Geneviève de Soufflot, deberian situarse flanqueando el coro. Se trata, sin duda, de una obra muy innovadora y elegante, resuelta de manera magistral, que recibió merecidas alabanzas por parte de otros colegas coetáneos como Quatrèmere de Quincy (Braham 1980: 132-133). Por ello no debe resultar extraño que su orgulloso autor publicara los planos del proyecto en la década de 1790, viendo la luz una versión ligeramente diferente después de $1800 .{ }^{18}$ Heredera de Saint-Philippe-du-Roule sería Saint-Pierre-
du-Gros-Caillou (1775), derribada durante la Revolución, con un grandioso proyecto de Mathurin Cherpitel (figuras 30, 31 y 32) y, ya en el siglo XIX, Étienne-Hippolyte Godde retomaria el modelo en Saint-Denys-du-SaintSacrement (1826-1835) y, con arcos en lugar de dinteles, en la reconstrucción de SaintPierre-du-Gros-Caillou (1822-1829) y NotreDame-de-Bonne-Nouvelle (1823-1830).

Aparte de estas obras, el esquema basilical tuvo bastantes secuelas en las décadas de 1760 a 1790. Algunas -como Notre Dame, en Guebwiller (1761-85), de Louis Beuque; La Madeleine, en Rouen (1767-1781), de JeanBaptiste Le Brument o Saint-Symphorien, en Gy (1769-1774), de Henri Frignet y Jean Charles Colombot- son edificios situados al noreste del país y responden el tipo visto en las propuestas de Contant d'Ivry. En otros casos -como la capilla del primer proyecto para el Convent de la Reine, en Versalles (176772), de Richard Mique, o el proyecto para la Iglesia de los Capuchinos de Estrasburgo (1774), de Jean-Baptiste Kléber, discípulo de Chalgrin- la relación con las basilicas de la década de 1760 es más evidente Lo mismo ocurre con Saint-Germain l'Auxerrois (17857) en Romainville, a las afueras de Paris, y algunas iglesias desaparecidas de la capital, como Saint-Barthélemy (1778), de Mathurin Cherpitel, la capilla de las Filles de SaintChaumont (1781) de Pierre-Claude Convers o Saint-Sauveur (1784) de Bernard Poyet (Kalnein 1995: 204). ${ }^{19}$ 
De todas ellas, esta última es sin duda la más interesante. Fue proyectada por Bernard Poyet (1742-1824), uno de los arquitectos con más talento de su generación, que trabajó inicialmente con De Wally y obtuvo el premio de Roma en 1768, siendo nombrado a su regreso arquitecto del duque de Orleans. En 1790 se convertiria en arquitecto de la Villa de París y a él se debe la nueva fachada del Palais Bourbon (1800), convertido en Palacio de la Asamblea (Braham 1980: 241). El proyecto de Saint-Sauveur se remonta a 1784, aunque las obras se interrumpieron en 1791 y no se concluyeron jamás (Clouet d'Orval 1972: 136). La propuesta de Poyet (figuras 33 y 34) muestra una singular solución que aúna una nave con pórticos adintelados e iluminación cenital con una exedra de mayor diámetro (figura 35), inspirada formalmente en el Panteón de Roma, que recoge la idea del aula de anatomía en la Escuela de Cirugía de París (1780), de Jacques Gondouin, aunque también puede relacionarse con la planta de la Basílica Ulpia de Roma. Es significativo que, en fecha indeterminada, Poyet retomó este mismo esquema en una propuesta para un Palacio de Justicia, precedido de un enorme atrio (Museo Carnavalet G.20771), demostrando una ambivalencia del modelo que probablemente remite a la identificación entre basilica cristiana y basílica civil romana.

El trabajo de Poyet nos trae a la memoria, por su rotundidad y forma de iluminación, la conocida propuesta (figura 36) de ÉtienneLouis Boullée para la Biblioteca Nacional de París (1785). Este célebre proyecto proponía cubrir el patio del Palais Mazarin, de unos 100 x 30 metros, con una gran bóveda que se ejecutaría en madera -como Saint-Philippedu-Roule- si bien el autor no descartaba la posibilidad de realizarla en fábrica, reforzando adecuadamente los cuerpos laterales de la preexistencia (Rosenau 1976: 103-105). Es significativa la solución del claroscuro en los extremos, donde se pensaba colocar algunas estatuas, de las que una debería ser la de Minerva. Aunque esta propuesta es posterior a Saint-Sauveur, la nueva tipología ya había despertado el interés de Boullée, como demuestran sus diseños para la inconclusa iglesia de La Madeleine, anteriores a 1781, donde simplifica y monumentaliza las ideas de Contant d'Ivry.

Nos gustaría concluir este recorrido con otro espacio de carácter civil y efímero, que de alguna manera representa el triunfo de los ideales de la Ilustración. Se trata del salón de la Asamblea Nacional, construido en 1789
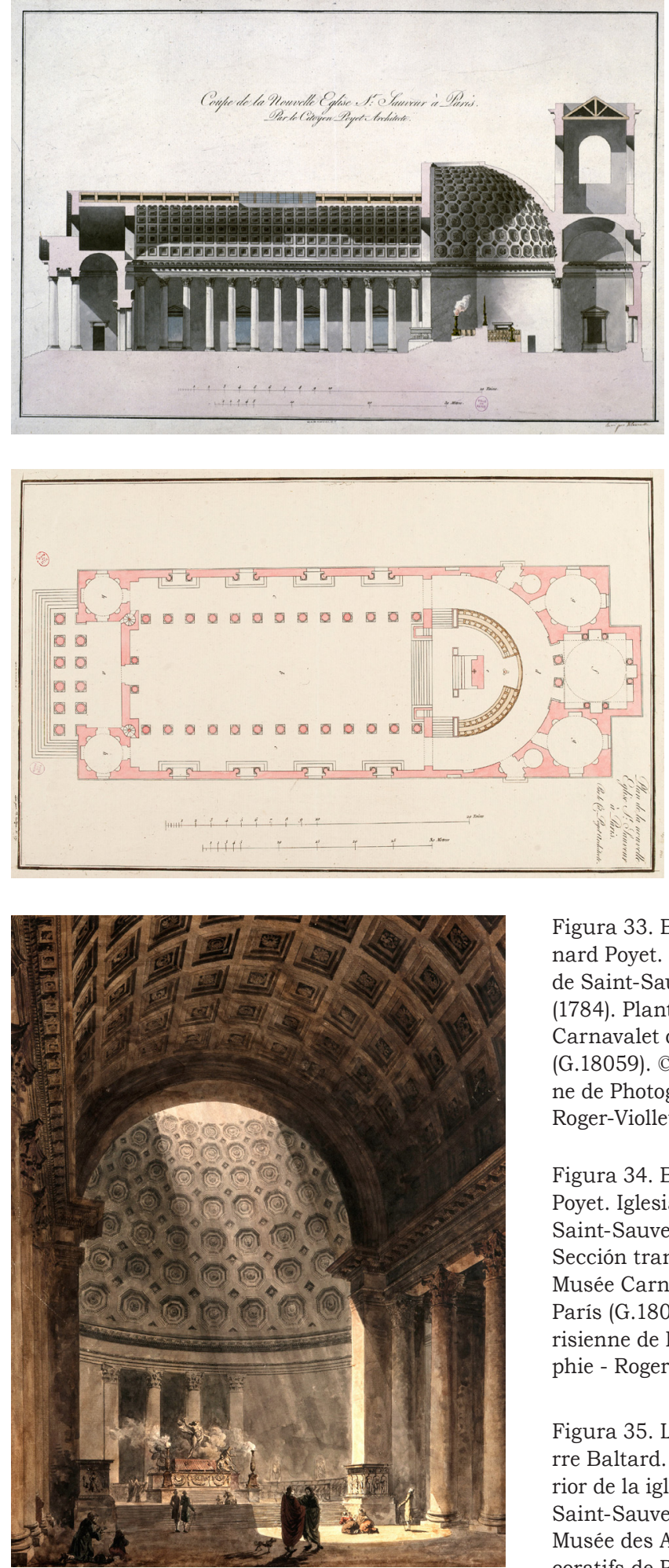

Figura 33. Bernard Poyet. Iglesia de Saint-Sauveur (1784). Planta. Musée Carnavalet de Paris (G.18059). (C) Parisienne de Photographie Roger-Viollet.

Figura 34. Bernard Poyet. Iglesia de Saint-Sauveur (1784). Sección transversal. Musée Carnavalet de Paris (G.18058). (C Pa risienne de Photographie - Roger-Viollet.

Figura 35. Louis-Pierre Baltard. Interior de la iglesia de Saint-Sauveur (1784) Musée des Arts Décoratifs de París. (C) Paris, Les Arts Décoratifs. por Pierre-Adrien Pâris para la reunión de los Estados Generales en un patio del Hôtel des Menus Plaisirs, en Versalles. Pâris, diseñador y escenógrafo de la Corte, fue colaborador de Trouard en la década de 1760 y acompañó al hijo de éste a Roma en 1769, por lo que no debe extrañarnos la semejanza formal de esta obra con las propuestas de Saint-Symphorien y Saint-Philippe-du-Roule. La estructura ce- 

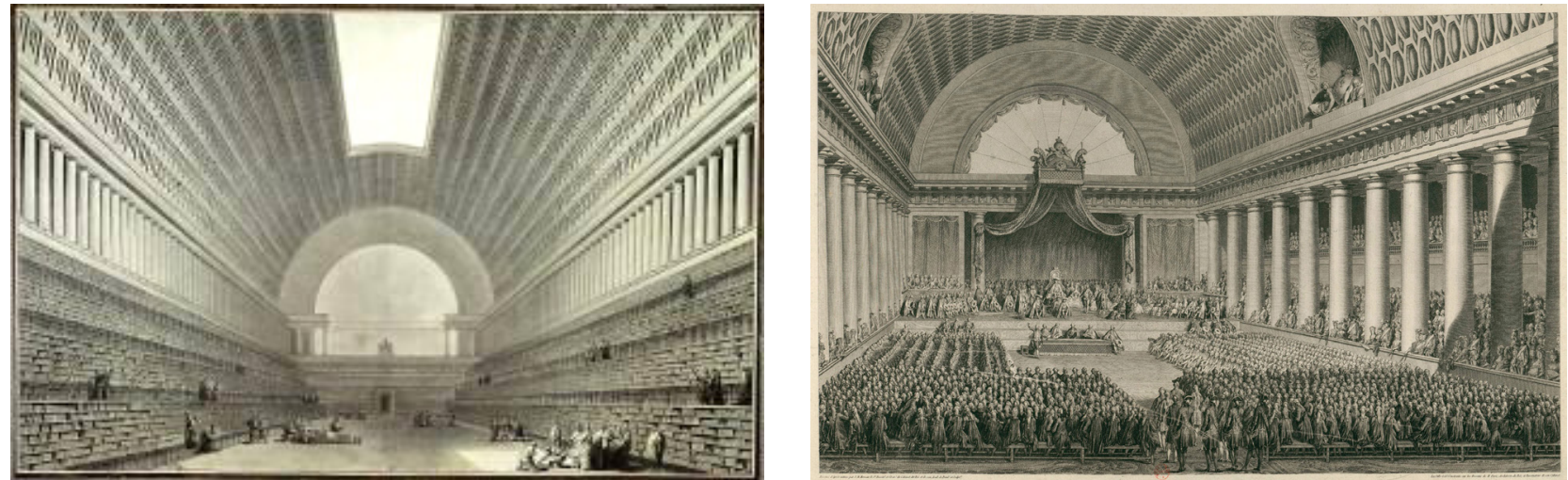

Figura 36. Étienne-Louis Boullée. Proyecto para la $\mathrm{Bi}$ blioteca Nacional de Paris (1785). Fuente: Gallica.fr.

Figura 37. Jean-Michel Moreau. Ouverture des Etats généraux par Louis seize: à Versailles le 5 Mai 1789. Bibliothèque nationale de France, RESERVE QB-370 (9)-FT 4. Fuente: Gallica.fr.

Figura 38. Juan de Villanueva. Real Oratorio del Caballero de Gracia (1782-1795). Fotografia de Zarateman. Fuente: Wikimedia commons.

variedad y novedad a causa de no hallarse rraba un espacio de 36 x 45 metros y bien podria haberse resuelto mediante una bóveda de madera hecha de tablones, según el método de Philibert de l'Orme, que en 1782-83 había servido para cubrir los 45 metros de diámetro de la cúpula del Halle au Blé de París (Pinon 1997: I, 386-387). Sin embargo, parece que la bóveda de medio cañón no es más que una invención del grabado de Moreau el Joven (figura 37) para dar mayor grandiosidad al espacio. De hecho, en otras fuentes coetáneas se representa con un techo plano con el perímetro redondeado a modo de bóveda esquifada que, como en Charenton, probablemente colgaba de una estructura triangulada de madera (Pinon 1997: I, 393).

\section{Epílogo hispánico}

En ámbito hispánico podemos encontrar paralelos con estos edificios franceses en las décadas de 1780 y 1790, de la mano de Juan de Villanueva. El primer ejemplo que cabe señalar es el Oratorio del Caballero de Gracia en Madrid, construido entre 1782 y 1795 (figura 39). Villanueva presentó dos plantas, una "recomponiendo toda la nave con la formación de unas pilastras y capillas, a fin de unirla al carácter de la nueva capilla mayor o crucero que propongo hacer" y otra, de esquema basilical, "que haría en obra mejor efecto, con más

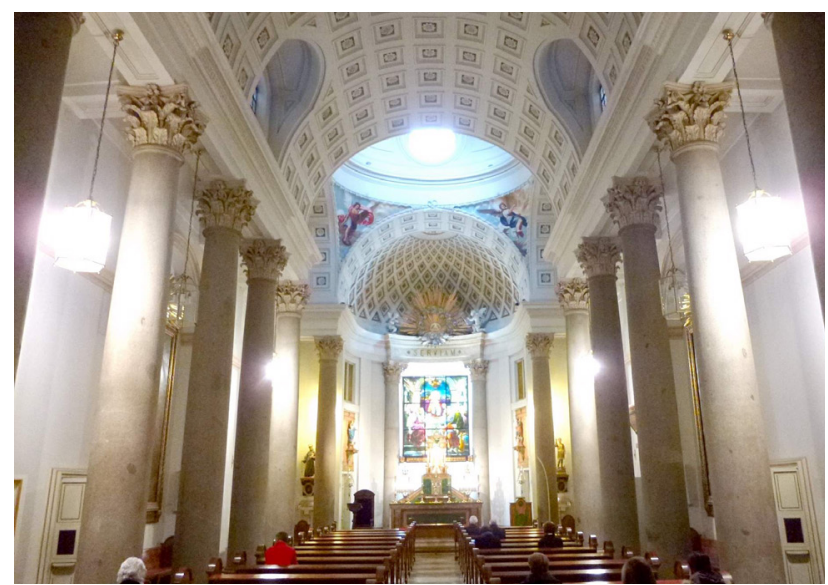
en esta Corte alguna otra de tal idea". Como bien observa Pedro Moleón (1998: 121-124), ciertamente Villanueva podría haber añadido que no había ninguna obra similar en toda España. Del proyecto original se conserva únicamente un levantamiento de la preexistencia sobre el que se han dibujado a lápiz las columnas, siguiendo un esquema similar a lo ejecutado finalmente. La falta de fondos retrasó en siete años el comienzo de las obras, en cuya dirección se mantuvo Villanueva hasta finales de noviembre de 1794, cuando fue cesado. El edificio sería concluido apresuradamente en los tres meses siguientes por Pedro Arnal.

Suele relacionarse la propuesta del Oratorio con la Scala Regia del Vaticano, pero no deja de ser llamativa la semejanza entre la imagen del templo madrileño y las basilicas francesas de la década de 1760 . No obstante, es cierto que en Madrid las naves laterales son espacios residuales y, por tanto, está más próximo al proyecto de Bernini. Sin embargo, al menos en 1794 sí que conocería las experimentaciones que se estaban realizando en Francia, porque los dibujos realizados en marzo de ese año para la iglesia de Villanueva del Río Segura, en Murcia (Moleón 2011), guardan una gran semejanza con Saint-Symphorien de Montreuil y también podemos encontrar una solución de doble bóveda similar a la de Villanueva en el proyecto para Saint-Germain-en-Laye (Du Panier s/f: 19) del mismo Potain. ${ }^{20} \mathrm{El}$ mismo año 1794, el director de la Academia de Bellas Artes de San Carlos de Valencia planteaba también un proyecto basilical inspirado en SaintPhilippe-du-Roule para la pequeña población valenciana de Sedavi. ${ }^{21}$ Quizá la fecha no sea casual, porque coincidiría con la llegada de exiliados franceses a raíz de las persecuciones llevadas a cabo por el gobierno jacobino de Robespierre entre 1792 y 1793. 

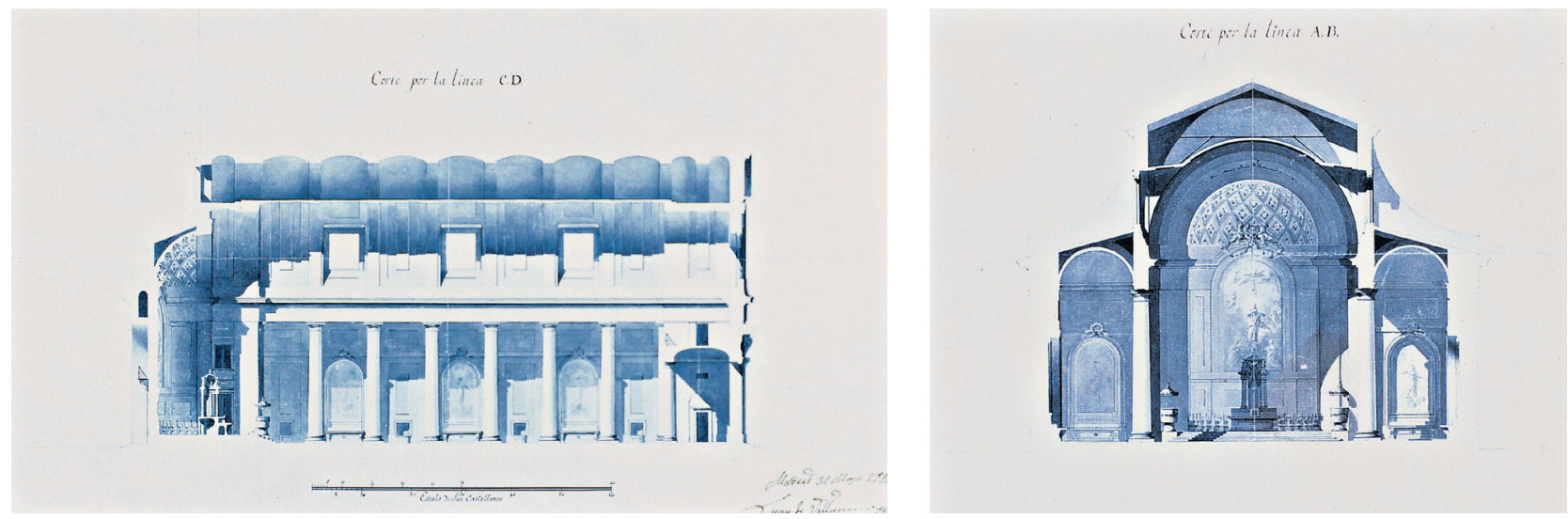

Con ello damos por finalizado este recorrido en el que hemos podido comprobar cómo la Basílica de Fano sirvió de modelo tanto a templos protestantes y católicos como a edificios profanos. Frente a las estructuras de madera británicas, en Francia Perrault será capaz de desarrollar soluciones adinteladas con el auxilio de fábricas armadas, aplicadas magistralmente en la capilla de Versalles. Esta obra resurgiría como referencia paradigmática a mediados del siglo XVIII, gracias a Laugier y a Blondel, aunque en la década de 1760 se puede observar una evolución hacia modelos más arqueológicos y severos. Constructivamente no debe olvidarse tampoco la introducción pionera de la técnica tabicada, así como el desarrollo de ingeniosas propuestas de doble abovedamiento, resistentes a los incendios y más duraderas que las estructuras convencionales. Se trata, como ya vaticinó Le Roy, de uno de los episodios más notables de la arquitectura francesa, tanto por sus aspectos formales como compositivos, posible gracias a una audacia y lógica constructiva fuera de toda duda.

\section{Notas}

1 Su parecido podría derivar de la asimilación del modelo protestante para las sinagogas holandesas, como ya planteó Rosenau (1940), aunque tampoco deben olvidarse los contactos de las comunidades judias de Amsterdam y Londres (Mitchell 2014) ni descartar una lectura paralela del texto vitruviano por parte de Wren. En todo caso, no hay que olvidar que las bóvedas de madera son frecuentes en la arquitectura medieval inglesa.

2 Probablemente se pretendian mantener los muros perimetrales y la cimentación, como sugiere la modulación similar a la de la planta primitiva, publicada por Viollet-le-Duc (1854: 284).

3 Estos son los puntos que resalta Bérchez (2009: 195) y realmente en el texto de Fleury no se habla mucho más sobre arquitectura. Estarian contenidos en los capitulos XXXV (Forma de las iglesias), XXXVI (Adorno de las iglesias) y XXXVII (Distinción de las iglesias y los templos).
4 Dejamos aparte, por la cronología y contexto arquitectónico, la capilla realizada por Vanvitelli para el palacio real o Reggia de Caserta (Nápoles), entre 1752 y 1784.

5 No era una solución óptima y, de hecho, la capilla de Lunéville fue destruida por un incendio en 2003 y ha tenido que ser reconstruida recientemente. También se resolvieron con estructuras adinteladas de madera, pero con techos planos, la capilla de la Comunión de Saint-Jean-enGrève, de Jacques-François Blondel (1735) o Saint-François-de-Paule en Toulon, concluida en 1744.

6 Traducción propia. Compárese con el texto de la primera edición de 1753, en la página 211. Esta referencia es citada por Petzet (1961: 82).

7 Estas bóvedas estarian inspiradas en Santa Sofia de Constantinopla, edificio que despertó el interés de Wren a partir de los escritos de Guillaume-Joseph Grelot y del promotor de su libro, el hugonote Jean Chardin, quien se trasladó a Inglaterra en 1680 (Ruffinière du Prey 2000: 40-43). Jacques-Germain Soufflot también las empleó en su proyecto para SainteGeneviève de París (1755-1790) y así aparecen en los planos de 1757, aunque el Canadian Centre for Architecture, de Montréal, conserva una propuesta anterior resuelta con bóveda de medio cañón peraltada (DR1975:0002).

8 Se sabe que diseñó una nueva plaza y un Ayuntamiento en el muelle de Conti, cuyos planos aprobó el Conde de Argenson en 1749 (Croÿ 1906: 129). También elaboró una propuesta para la plaza de Luis XV (Croÿ 1906: 191) y consultó con el rey sus ideas para reconstruir su residencia del Hermitage, elaborando planos que fueron revisados por Gabriel, arquitecto de Luis XV (Croÿ 1906: 213-214, 223-224, 229, 232, 241).

9 Probablemente sobre estas bóvedas haya tabiquillos conejeros, como planteaba Espie en su libro.

10 Las bóvedas del primer piso en este edificio también son vaídas, como en Saint-Wasnon, pero están resueltas a rosca.

11 Belle-Isle, tío de la esposa de Croÿ-Solre, estuvo prisionero durante gran parte del año 1745 en Inglaterra tras haber sido detenido al regreso de una misión diplomática en Munich (PicaudMonnerat 2014).
Figura 39. Juan de Villanueva. Sección longitudinal de la iglesia de Villanueva del río Segura (1794). Museo de Historia de Madrid, IN 4088. (Moleón 2011).

Figura 40. Juan de Villanueva. Sección transversal de la iglesia de Villanueva del río Segura (1794). Museo de Historia de Madrid, IN 4087. (Moleón 2011). 
12 Espie debió conocerlas por la prensa. En abri de 1750, el Mercure de France publicaba un breve artículo atribuyendo su invención a un arquitecto de Orange (pp. 216-217). Poco después, en el número de junio (pp. 43-55) se desmentía la autoría describiendo con detalle las experiencia de Bizy y sus artífices (Espie 1754: 10-12).

13 Esta planta, bastante convencional, fue considerada por Laugier como inferior a la de SainteGeneviève (Braham 1980: 52). Segun Pérouse de Montclos (1989: 400-402) la solución de crucero remitía a algunas iglesias del norte de Francia, como Saint-Géry de Combrai. Existe una acuarela de 1762 que representa el interior propuesto por el arquitecto.

14 Sus bóvedas son exageradamente peraltadas en lo que podría ser una modificación del proyecto original de Contant para adaptarse a una cubierta de gran pendiente en las naves.

15 Dejamos aparte la ortodoxa planta basilical que, como acertadamente ha propuesto Bérchez (2009, 193-194), se explicaría por el influyente texto de Fleury, traducido al español en 1739 y reeditado tres décadas después.

16 Para la cronología y autoría de los proyectos de la catedral de Rennes, http://www.infobretagne.com/rennes-cathedrale-reconstruction. htm, consultado el 30-01-2018. En cuanto a Saint-Germain-en-Laye, la obra fue ejecutada entre 1823-1827 bajo un modelo de basílica paleocristiana totalmente arqueológico, que nada tenía que ver con la propuesta de Potain.

17 En Rennes la bóveda es con toda seguridad de madera, porque no hay contrafuertes. En cuanto a Saint-Germain-en-Laye, el proyecto conservado (Du Panier s/f: 19) plantea una interesante solución de doble bóveda que hace pensar en una estructura tabicada, si bien no puede descartarse la adaptación de un diseño pensado inicialmente para cubrirse con madera.

18 Los planos originales de Chalgrin, grabados por Louis-Gustave Taraval (1738-1794), se publicaron hacia 1785 en un cuaderno con el título de Plan, coupes et elevations profils de l'église de St. Philippe du Roule. Los grabados más conocidos son los publicados por Krafft y Ransonnette (1801: CIII y CIV).

19 La clasificación de las obras es nuestra. Este autor añade además un proyecto para la Cathédrale Saint-Jean, en Alès (1769-76) de Jean-Antoine Giral y Jacques Donnat, del que no hemos podido encontrar más información.

20 Pedro Moleón sugirió inicialmente una relación entre las plantas basilicales de Villanueva y el proyecto de Saint-Philippe-du-Roule, de Chalgrin (Moleón 1998: 14), pero más recientemente ha considerado la posibilidad de influencias británicas (Moleón 2011: 27). Aunque el significativo detalle de los lunetos adintelados se repite en la maqueta decimonónica del proyecto de la catedral de Dublín (Grimes 2005: fig. 2.11), la ascendencia francesa de esta obra es evidente.

21 El edificio actual está construido a partir de un segundo proyecto, de 1816 (Bérchez 2009, 197), si bien es probable que responda en lo esencial a la propuesta inicial de 1794 , como ocurre en Villanueva del Segura.

\section{Bibliografia}

Bannister, Turpin C. 1968. The Roussillon Vault: The Apotheosis of a 'Folk' Construction. Journal of the Society of Architectural Historians, 27-3: 163-175.

BÉRCHEZ, Joaquín. 2009. Ideario ilustrado y académico valenciano en la renovación de la catedral de Segorbe. En: Román de la Calle (dir.). La Real Academia de Bellas Artes de San Carlos en la Valencia ilustrada, Valencia: Universitat de València. 185-208.

Blondel, Jean-François. 1756. Architecture françoise, ou Recueil des plans, élévations, coupes et profils des églises, maisons royales, palais, hôtels ,édifices les plus considérables de Paris..., tomo IV. París: Charles-Antoine Jombert

BraHAm, Allan. 1980. The Architecture of the French Enlightenment. Londres: Thames and Hudson.

CABAnEL, Patrick. 2012. Histoire des protestants en France: XVIe-XXIe siècle.París: Artheme Fayard.

Calduch Cervera, Joan. 2014. El Tratado de Vitruvio ilustrado: los dibujos de la basílica. Cuaderno de notas, 15: 95-109.

Chalgrin, Jean-François-Thérèse Chalgrin. 1785. Plan, coupes et elevations profils de l'église de St. Philippe du Roule. París.

Chareyre, Philippe. 2017. Le temple de la Calade et la Maison du consistoire de Nimes. Patrimoines du Sud (En linea), 5 (https://inventaire-patrimoine-culturel.cr-languedocroussillon.fr, consultado en febrero de 2018).

Clouet D'Orval, Guy. 1972. Les anciennes inscriptions des noms de rues de Paris (1728-1806). En: Paris et Ile-de-France. Mémoires publiés par la Fédération des Sociétés historiques et archéologiques de Paris et de l'Ile-de-France, t. XX (1969). Paris: Libreria C. Klincksieck. 127-274.

Contant D'Ivry, Pierre. 1769. Les Oeuvres d'Architecture de Pierre Contant d'Ivry, architecte du roi. Paris: Chez Dumont.

Coope, Rosalys. 1972. Salomon de Brosse and the Development of the Classical Style in French Architecture from 1565 to 1630. Londres: A. Zwemmer Ltd.

CROŸ-SOlRe, Emmanuel.1906. Journal inédit du duc de Crö̈, 1718-1784. Paris : Ernest Flammarion.

Curt, James Stevens. 2002. Georgian Architecture. Devon: David \& Charles Brunel House.

Divitis, Bianca de. 2015. Giuliano da Sangallo in the Kingdom of Naples: Architecture and Cultural Exchange. Journal of the Society of Architectural Historians, 74-2: 152-178.

Dupanier, Vincent. [s/f]. Église Saint-Germain, un trésor patrimonial. Saint-Germain-en-Laye: Mairie de Saint-Germain-en-Laye. (https://es. calameo.com/books/0005524942accfb4f713b, consultado en abril de 2018).

EDmunds, Martha Mel Stumberg. 2002. Piety and Politics. Imaging divine kingship in Louis XIV's chapel at Versailles. Newark: University of Delaware Press.

Espie, Félix-François d'. 1754. Manière de rendre toutes sortes d'édifices incombustibles ou Traité sur la Construction des voûtes faites avec des 
briques et du plâtre, dites voûtes plates; et d'un toit de brique, sans charpente, appelé comble briqueté. De l'invention de M. le comte d'Espie. París: Duchesne.

González Moreno-Navarro, José Luis. 2004. La bóveda tabicada: Pasado y futuro de un elemento de gran valor patrimonial. En: Truñó, Ángel: Construcción de bóvedas tabicadas. Madrid: Instituto Juan de Herrera. IX-LX.

Gravagnuolo, Benedetto. 2010. Prefacio. En: J. L. De Cordemoy: Nuovo trattato di tutta l'architettura o l'arte del costruire. Roma: Gangemi. 7-16.

Grimes, Brendan. 2005. The Architecture of Dublin's Neo-Classical Roman Catholic Temples 1803-62. Tesis Doctoral. Dublin: National College of Art and Design.

Guicharnaud, Hélène. 1999. An Introduction to the Architecture of Protestant Temples Constructed in France before the Revocation of the Edict of Nantes. En: Paulo Corby Finney (ed.). Seeing Beyond the Word. Visual Arts and the Calvinist Tradition. Cambridge: William B. Eerdmans. 133-162.

Joudiou, Gabrielle. 1986. Saint-Wasnon et SaintVaast: deux remarquables églises de Contant d'Ivry. Revue du Nord, 271: 835-858.

Kalnein, Wend von. 1995. Architecture in France in the Eighteenth Century. New Haven: Yale University Press.

Kaufmann, Emil. 1955. Architecture in the Age of Reason. Cambridge: Harvard University Press.

KRAfFt, Jean-Charles y RAnsonnette, Pierre Nicolas. 1801. Plans, Coupes, Élévations des plus belles Maisons et des Hotels construits à Paris et dans les environs. Paris: Levrault, París.

LAUGIER, Marc-Antoine. 1755. Essai sur l'architecture. París: Duchesne.

Lequeu, Jean Jacques. 1780. Coupes et profils $d u$ portique et d'une partie de la nef d'entrée de la nouvelle église de Ste Geneviève de Paris, d'après l'execution et les desseins de feu $M$. Soufflot [...]. París: s/e.

LE Roy, Julien-David. 1764. Histoire de la disposition et des formes différentes que les chrétiens ont données à leurs temples, depuis le règne de Constantin le Grand, jusqu'à nous. París: Desaint \& Saillant.

MAROT, Jean. [h. 1680]. L'Architecture française, ou recueil des plans, élévations, coupes et profils des églises, palais, hôtels et maisons particulières de Paris. París: P.-J. Mariette.

Mitchell, Elizabeth Ann. 2014. In the Style of Toleration: Bevis Marks and the Synagogue Architecture of Seventeenth-Century London. Tesis Final de Master. Universidad de Virginia.

Moleón Gavilanes, Pedro. 1998. Juan de Villanueva. Madrid: Akal.

Moleón Gavilanes, P. 2011. Arquitectura religiosa de Juan de Villanueva. La iglesia parroquial de Villanueva del Río Segura, Murcia, Nuevas aportaciones en la obra del arquitecto. Reales Sitios, 190: 4-27.

Moulin, Jacques. 1991. Le château d'Aunoy et l'apparition en France du jardin à l'anglaise. Bulletin Monumental, 149-2: 201-224.
OffenberG, Adri K. 1988. Jacob Jehuda Leon (16021675) and His Model of the Temple. En: In J. van den Berg and Ernestine G.E. van der Wall (eds.). Jewish-Christian Relations in the 17th Century. Londres: Kluwer Academic Publishers. 95-118.

Ortiz y SAnZ, Joseph. 1787. Los Diez Libros de Arquitectura de M. Vitruvio Polión. Traducidos del latín y comentados por [...]. Madrid: Imprenta Real.

Patte, Pierre. 1769. Mémoires sur les objets les plus importans de l'architecture. Paris: Chez Rozet.

Pérouse de Montclos, Jean-Marie. 1989. Histoire de l'Architecture Française. De la Renaissance à la Révolution. París: Mengés C.N.M.H.S.

Petzet, Michael. 1957. Un projet des Perrault pour l'église Sainte-Geneviève à Paris. Bulletin Monumental, 115-2: 81-96.

Picaud-Monnerat, Sandrine. 2014. L'affaire du maréchal de Belle-Isle (décembre 1744 - août 1745). Carnet de la Sabretache, 200: 30-33.

Pinon, Pierre. 1997. Pierre-Adrien Pâris architecte (1745-1819) ou l'archéologie malgré soi. Tesis Doctoral, Universidad de París-Sorbona, París 1997.

Rosenau, Helen. 1940. The Synagogue and Protestant Church Architecture. Journal of the Warburg and Courtauld Institutes, 4-1/2 (1940): 80-84.

Rosenau, H. 1976. Boullée \& visionary architecture, including Boullée's Architecture, Essay on Art'. Londres: Academy Editions.

Royal Commission on Historical Monuments. 1929. An Inventory of the Historical Monuments in London, Volume 4, the City. Londres: His Majesty's Stationery Office. (http://www.british-history.ac.uk/rchme/london/vol4, consultado en marzo de 2018)

Ruffinière du Prey, Pierre de la. 2000. Hawksmoor's London Churches. Architecture and Theology. Chicago: The University of Chicago Press.

Soufflot, Jacques Germain. 1757. Plan général de l'église de Sainte-Geneviève, de la place \& de la rüe au devant, suivant le dernier projet présenté au Roy par Mr le Marquis de Marigny, approuvé par Sa Majesté le 2 mars 1757. Paris: J. C. Bellicard.

VIOLLET-LE-Duc, Eugène-Emmanuel. 1854 Dictionnaire raisonné de l'architecture française du XIe au XVIe siècle, Tomo I. París: B. Bancé.

ZaragozÁ Catalán, Arturo. 2012. Hacia una historia de las bóvedas tabicadas. En: Construyendo bóvedas tabicadas. Actas del Simposio Internacional sobre Bóvedas Tabicadas. Valencia: Universitat Politècnica de València. 11-46.
Fecha final recepción articulos: 16/04/2018

Fecha aceptación: 22/06/2018

Artículo sometido a revisión por dos revisores independientes por el método doble ciego. 